\title{
A meta-analysis of 1,119 manipulative experiments on terrestrial carbon-cycling responses to global
} change

\author{
Jian Song $\mathbb{1}^{1,2}$, Shiqiang Wan $\mathbb{1}^{1,2 \star}$, Shilong Piao $\mathbb{1}^{3,4,5}$, Alan K. Knapp ${ }^{6,7}$, Aimée T. Classen ${ }^{8,9}$, \\ Sara Vicca ${ }^{10}$, Philippe Ciais $\mathbb{1}^{11,3}$, Mark J. Hovenden ${ }^{12}$, Sebastian Leuzinger ${ }^{13}$, Claus Beier ${ }^{14}$, \\ Paul Kardol ${ }^{15}$, Jianyang Xia ${ }^{16,17}$, Qiang Liu ${ }^{3}$, Jingyi Ru ${ }^{2}{ }^{2}$, Zhenxing Zhou'2, Yiqi Luo ${ }^{18}$, Dali Guo ${ }^{19}$, \\ J. Adam Langley ${ }^{20}$, Jakob Zscheischler ${ }^{21,22}$, Jeffrey S. Dukes ${ }^{23}$, Jianwu Tang ${ }^{24}$, Jiquan Chen ${ }^{25}$,
} Kirsten S. Hofmockel (16,27, Lara M. Kueppers ${ }^{28,29}$, Lindsey Rustad ${ }^{30}$, Lingli Liu ${ }^{31}$, Melinda D. Smith ${ }^{6,7}$, Pamela H. Templer ${ }^{32}$, R. Quinn Thomas ${ }^{33}$, Richard J. Norby $\mathbb{1}^{34}$, Richard P. Phillips ${ }^{35}$, Shuli Niu ${ }^{36}$, Simone Fatichi ${ }^{37}$, Yingping Wang ${ }^{38}$, Pengshuai Shao ${ }^{39}$, Hongyan $\mathrm{Han}^{39}$, Dandan Wang ${ }^{2}$, Lingjie Lei ${ }^{2}$, Jiali Wang ${ }^{2}$, Xiaona $\mathrm{Li}^{2}$, Qian Zhang ${ }^{2}$, Xiaoming $\mathrm{Li}^{2}$, Fanglong Su², Bin Liư ${ }^{2}$, Fan Yang ${ }^{2}$, Gaigai Ma², Guoyong Li², Yanchun Liư ${ }^{2}$, Yinzhan Liư², Zhongling Yang ${ }^{2}$, Kesheng Zhang ${ }^{2}$, Yuan Miao², Mengjun $\mathrm{Hu}^{2}$, Chuang Yan², Ang Zhang ${ }^{2}$, Mingxing Zhong ${ }^{2}$, Yan Hui ${ }^{2}$, Ying $\mathrm{Li}^{2}$ and Mengmei Zheng ${ }^{2}$

Direct quantification of terrestrial biosphere responses to global change is crucial for projections of future climate change in Earth system models. Here, we synthesized ecosystem carbon-cycling data from 1,119 experiments performed over the past four decades concerning changes in temperature, precipitation, $\mathrm{CO}_{2}$ and nitrogen across major terrestrial vegetation types of the world. Most experiments manipulated single rather than multiple global change drivers in temperate ecosystems of the USA, Europe and China. The magnitudes of warming and elevated $\mathrm{CO}_{2}$ treatments were consistent with the ranges of future projections, whereas those of precipitation changes and nitrogen inputs often exceeded the projected ranges. Increases in global change drivers consistently accelerated, but decreased precipitation slowed down carbon-cycle processes. Nonlinear (including synergistic and antagonistic) effects among global change drivers were rare. Belowground carbon allocation responded negatively to increased precipitation and nitrogen addition and positively to decreased precipitation and elevated $\mathrm{CO}_{2}$. The sensitivities of carbon variables to multiple global change drivers depended on the background climate and ecosystem condition, suggesting that Earth system models should be evaluated using site-specific conditions for best uses of this large dataset. Together, this synthesis underscores an urgent need to explore the interactions among multiple global change drivers in underrepresented regions such as semi-arid ecosystems, forests in the tropics and subtropics, and Arctic tundra when forecasting future terrestrial carbon-climate feedback.

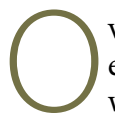
ver the past four decades, numerous experiments have explored how terrestrial ecosystems respond to climate warming, changing precipitation regimes, elevated $\mathrm{CO}_{2}$ $\left(\mathrm{eCO}_{2}\right)$ and nitrogen $(\mathrm{N})$ enrichment ${ }^{1-5}$. These extensive experimental results are scattered across many publications, and thus it is impractical to compare the outcome of experiments among different ecosystems ${ }^{6,7}$ and to assess possible nonlinear effects between global change drivers ${ }^{8,9}$. Although great efforts have been devoted to comparing model outputs against experimental observations with an attempt to reduce uncertainties on future projections of coupled carbon-climate system (for example, refs. ${ }^{10-12}$ ), the global models used in the upcoming IPCC (Intergovernmental Panel on Climate Change) AR6 (the Sixth Assessment Report) have not been tested against a large set of experiments.

Here, we synthesized 2,230 peer-reviewed studies with 1,119 experiments published during 1973-2016 to compare the magnitudes of treatments achieved by experimental manipulations with the changes in global change drivers projected by the end of this century, and to quantify the responses and sensitivities of key terrestrial carbon-cycle variables, including net primary productivity and biomass as well as their above- and belowground components, root-to-shoot ratios, litter mass, gross and net ecosystem productivity, and ecosystem and soil respiration, to warming, increased or decreased precipitation, $\mathrm{eCO}_{2}, \mathrm{~N}$ deposition and their combinations. Finally, data of multifactor experiments which factorially performed both multiple single-factor treatments and their combinations were pooled to examine whether multiple global change drivers cause multiplicative, synergistic or antagonistic responses.

Overview of global change manipulative experiments The 2,230 publications collected in our literature search included 850 single-factor and 269 multifactor experiments across all major terrestrial ecosystems of the world (Supplementary Dataset 1), albeit with uneven spatial coverage (Fig. 1a; see Supplementary Table 1 
and Supplementary Text 1 for the distribution of experiments across countries and publication list, respectively). The majority of singlefactor $(73.2 \%)$ and multifactor $(76.6 \%)$ experiments were conducted in temperate ecosystems of the Northern Hemisphere $\left(\sim 30-60^{\circ} \mathrm{N}\right)$, in the USA, Europe and China. The climate space sampled by all the experiments ranges from $110 \mathrm{~mm}$ to $2,301 \mathrm{~mm}$ in mean annual precipitation and from $-7.6^{\circ} \mathrm{C}$ to $22.3^{\circ} \mathrm{C}$ in mean annual temperature (Supplementary Fig. 1). This climate space domain covers $96 \%$ of the northern temperate lands, but only $50 \%$ of the Earth's land area. Regions with scarce experiments are semi-arid ecosystems, forests in the tropics and subtropics, and Arctic tundra, despite the sensitivity of these ecosystems to climate variability and climate change being highlighted by recent studies of modelling and analyses of Earth observation data ${ }^{13-15}$.

The magnitudes of temperature increase experimentally applied at more than $60 \%$ of the mid-latitude warming experiments are within the projected warming range in the same latitude band by the end of the twenty-first century (Fig. 1b). However, the experimental warming magnitudes at the high latitudes were generally lower than those projected in all the IPCC Representative Concentration Pathway scenarios (RCPs) ${ }^{16}$. More importantly, the majority of the experiments imposed greater changes in precipitation amount and $\mathrm{N}$ input than the global mean rates of changes projected under different RCPs (Fig. 1c,e) ${ }^{17}$. By contrast, $\mathrm{eCO}_{2}$ levels were within the projected range of RCP2.6 (475 ppm) and RCP6.0 (800 ppm), but the highest levels from RCP8.5 have not been covered by any experiment (1,313 ppm; Fig. 1d).

\section{Local climate mediating warming effects on ecosystem carbon cycling}

Across all the terrestrial ecosystems, experimental warming enhanced total, aboveground and root biomass, as well as soil respiration (Fig. 2a). Although belowground net primary productivity slightly increased under warming $(P=0.066)$, net primary productivity and its aboveground component remained unaltered. The root-to-shoot ratios showed a neutral warming response (Fig. 2f). Hence, carbon allocation patterns appeared to be largely unaffected by warming. In addition, gross and net fluxes of $\mathrm{CO}_{2}$ exchange between terrestrial ecosystems and the atmosphere (gross and net ecosystem productivity, and ecosystem respiration) did not show significant changes under warming, partly due to the use of multiple sites and the considerable response variations among the experiments. The observations suggest that the slight enhancement of belowground carbon input could be offset by increased soil carbon release (enhanced decomposition of soil organic matter, accelerated root turnover or stimulated root respiration $)^{18,19}$.

Soil moisture plays a predominant role in regulating plant photosynthesis and carbon allocation ${ }^{20}$ as well as ecosystem respiration ${ }^{21}$ under warming. In water-limited ecosystems, warming usually decreases carbon-cycle variables by exacerbating water limitation $^{22}$. To test such indirect warming effects, we conducted metaregressions between carbon-cycle variable changes under warming and wetness indices, which are proxies of the water available for plants $^{23}$. Results demonstrated that the warming responses of net primary productivity (Fig. $3 \mathrm{a} ; R^{2}=0.20, P=0.027$ ) and its belowground component (Fig. $3 \mathrm{~b} ; R^{2}=0.44, P=0.001$ ), aboveground biomass (Fig. 3c; $R^{2}=0.13, P=0.004$ ) and ecosystem (Fig. 3d; $R^{2}=0.24$, $P=0.009$ ) and soil respiration (Fig. $3 \mathrm{e} ; R^{2}=0.59, P<0.001$ ) shifted from negative to positive with increasing wetness indices, suggesting negative and positive warming effects under dry and wet climate conditions, respectively. In contrast, the warming effects on plant root-to-shoot ratios changed from positive to negative with increasing wetness (Fig. 3f; $R^{2}=0.23, P=0.003$ ), indicating that when exposed to warming, plants growing in dry areas tend to prioritize carbon allocation to roots at the expense of allocation to shoots. Alternatively, decreased root turnover in order to adjust to warming-induced drought may also contribute to this response. Together, these findings indicate that water limitations emerge as a likely indirect response to higher evaporative demand, counterbalancing the direct warming effects on plant growth and productivity ${ }^{21}$.

Finally, we estimated temperature sensitivities (percentage change of carbon variable per $1{ }^{\circ} \mathrm{C}$ temperature increase) for all observed variables with the exception of net ecosystem productivity. Net ecosystem productivity is the transient response of altered gross ecosystem productivity followed by lagged and warming-dependent ecosystem respiration. Theoretically, if warming duration exceeds carbon residence time in an ecosystem, gross ecosystem productivity and ecosystem respiration should balance each other, defining a new equilibrium state where net ecosystem productivity approaches zero. Across all the terrestrial ecosystems, root biomass showed the highest temperature sensitivity with an enhancement of $19.8 \%{ }^{\circ} \mathrm{C}^{-1}$ (Table 1). Despite the huge variability among the sites, our analyses suggest that the temperature sensitivity of aboveground biomass becomes negative at sites with higher mean annual temperature (Fig. 3g; $\left.R^{2}=0.10, P=0.007\right)$. Nevertheless, the temperature sensitivities of the other nine carbon-cycle variables were independent of mean annual temperature (Supplementary Fig. 2). This is partly supported by an ecosystem-level study which has revealed that temperature sensitivity of ecosystem respiration is converging globally but is not mediated by mean annual temperature ${ }^{24}$. These observations are inconsistent with the findings of a recent study on global drylands where temperature sensitivity of soil heterotrophic respiration declines with increasing mean annual temperature ${ }^{25}$.

\section{Non-uniform influences of precipitation anomalies}

Increased precipitation stimulated all ecosystem carbon-cycle variables except litter mass, whereas decreased precipitation generally reduced carbon-cycle variables (Fig. $2 \mathrm{~b}, \mathrm{c})^{5}$. At the ecosystem scale, we tested the first hypothesis $\left(\mathrm{H}_{1}\right)$ that semi-arid and temperate grasslands are more sensitive to increased precipitation than forests and deserts ${ }^{26}$. The responses to increased precipitation were normalized to $33 \%$ above the mean annual precipitation of each experiment (the median absolute value of precipitation treatments; see Methods for details). In contrast to the $\mathrm{H}_{1}$, the responses of net primary productivity and its belowground component as well as plant biomass (total, aboveground and root biomass) under a 33\% precipitation increase were comparable between forests and grasslands (Fig. 2g), although the enhancements of these variables were statistically significant in grasslands only. In addition, the significant stimulations of aboveground net primary productivity under a $33 \%$ precipitation increase did not differ among forests, grasslands and deserts (between-group heterogeneity $\left(Q_{B}\right)=2.30, P=0.31$ ). However, increased precipitation enhanced soil respiration more in grasslands than in forests $\left(Q_{B}=7.90, P=0.02\right)$, but comparably between grasslands and deserts, which partly supported our $\mathrm{H}_{1}$.

We also proposed a second hypothesis $\left(\mathrm{H}_{2}\right)$, that arid ecosystems would be more sensitive to increased precipitation and less sensitive to decreased precipitation than humid ecosystems ${ }^{23}$. To test $\mathrm{H}_{2}$, we conducted meta-regressions of carbon-cycle variable responses to normalized increased and decreased precipitation (33\% above and below the mean annual precipitation) to examine whether the changes of carbon-cycle variables are related to wetness indices. We found that the positive responses of aboveground net primary productivity (Fig. 3 h; $R^{2}=0.04, P=0.013$ ) and soil respiration (Fig. 3i; $\left.R^{2}=0.30, P<0.001\right)$ under a $33 \%$ precipitation increase declined with increasing wetness and the negative impacts of a $33 \%$ precipitation decrease on ecosystem respiration were exacerbated with increasing wetness (Fig. 3 j; $R^{2}=0.53, P=0.010$ ). The results suggest that the effects of increased precipitation on aboveground net primary productivity and soil respiration were lower, but the impacts of decreased precipitation on ecosystem respiration were higher in humid areas-a result supporting our $\mathrm{H}_{2}$. No relationship of 

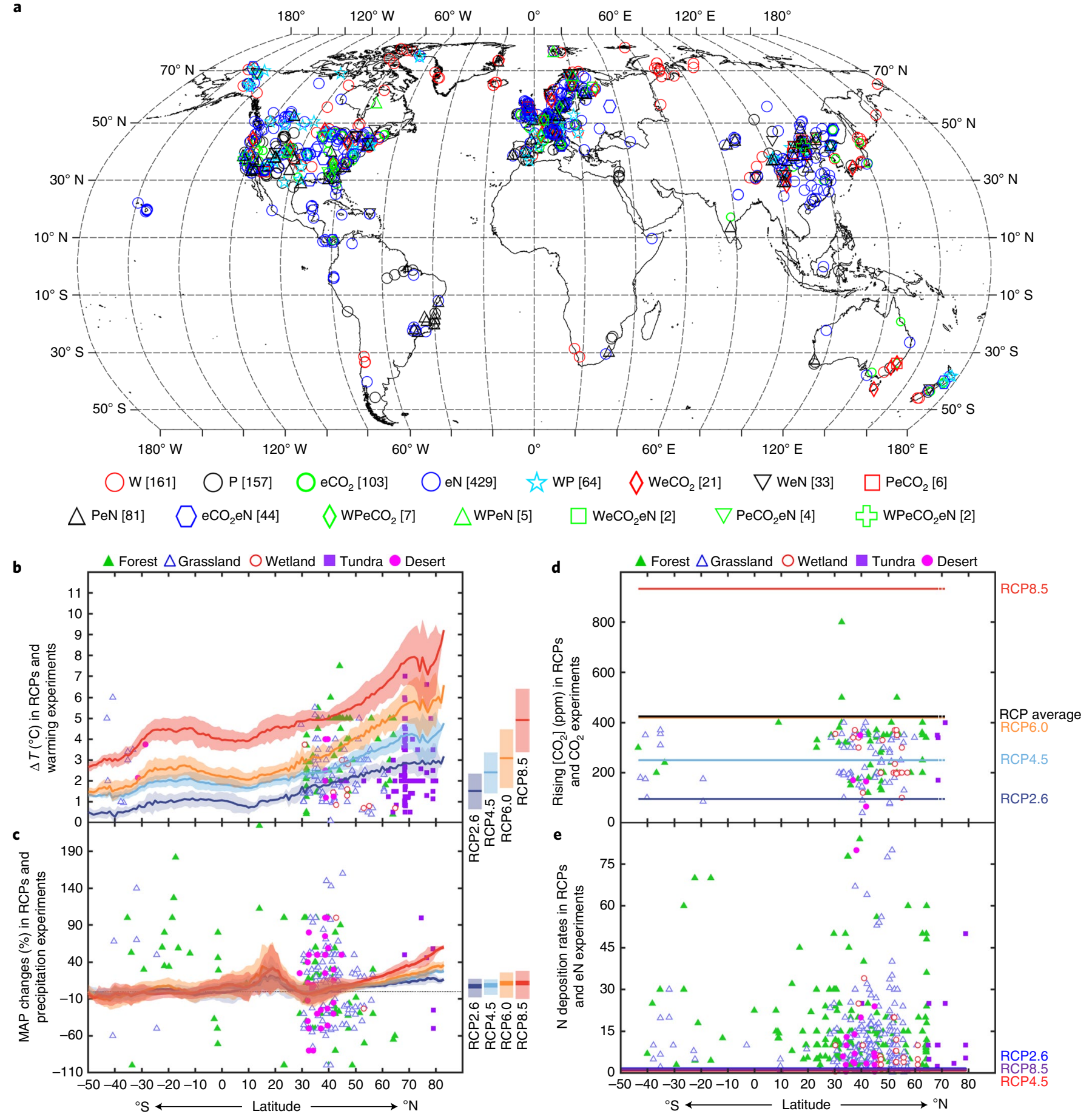

Fig. 1 | Global distribution of manipulative experiments and the magnitudes of experimental manipulations against model projections. a, The global distribution and number (shown in square brackets) of single-factor and multifactor manipulative experiments (1973-2016). b. The increases of Earth's land surface temperature $\left(\Delta T,{ }^{\circ} \mathrm{C}\right)$ projected in all RCPs of the IPCC and manipulated by warming experiments. c, The changes (\%) of mean annual precipitation (MAP) projected in all RCPs and manipulated by precipitation experiments. $\mathbf{d}$, The increases in atmospheric $\mathrm{CO}_{2}$ concentrations $\left[\mathrm{CO}_{2}\right]$ (ppm) projected in all RCPs and manipulated by $\mathrm{eCO}_{2}$ experiments. e, Maximum average $\mathrm{N}$ deposition over the world projected in $\mathrm{RCP} 2.6,4.5$ and 8.5 and $\mathrm{N}$ addition rates $\left(\mathrm{g} \mathrm{N} \mathrm{m}^{-2} \mathrm{yr}^{-1}\right)$ in eN manipulative experiments. (W, warming; $\mathrm{P}$, changing precipitation regimes; $\mathrm{eCO}_{2}$, elevated $\mathrm{CO}_{2}$; eN, enriched atmospheric $\mathrm{N}$ deposition; treatments in multifactor experiments are shown with multiple letters.)

precipitation-induced changes in any other carbon-cycle variables with wetness was detected (Supplementary Figs. 3 and 4). The non-uniform patterns in the dependence of changing precipitation effects upon wetness indices, which are proxies for the current moisture conditions at given sites, among carbon-cycle variables pose a great challenge for robust projections of carbon-cycle responses to changing precipitation regimes in global models ${ }^{27,28}$.

We calculated the relative precipitation sensitivity as the percentage change of carbon-cycle variables per $10 \mathrm{~mm}$ precipitation increase or decrease. All carbon-cycle variables except litter mass 

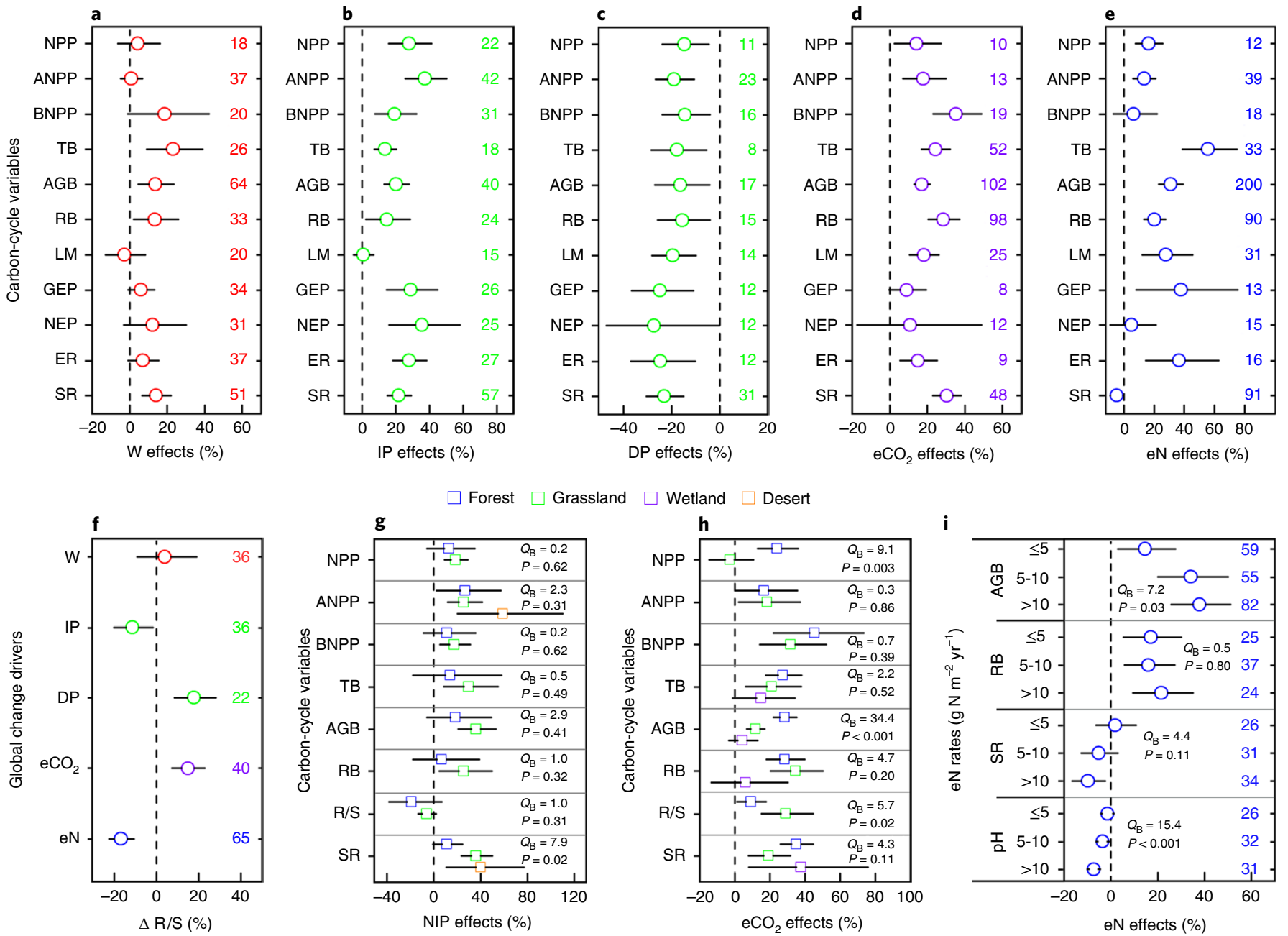

Fig. 2 | Effects of different drivers on carbon-cycle variables. a-e, Results on the percentage changes (mean $\pm 95 \%$ confidence intervals (Cls)) in ecosystem carbon-cycle variables, including net primary productivity (NPP) and its above- and belowground components (ANPP and BNPP), total, aboveground and root biomass (TB, AGB and RB), litter mass (LM), gross and net ecosystem productivity (GEP and NEP), and ecosystem and soil respiration (ER and SR) induced by $\mathrm{W}(\mathbf{a})$, increased precipitation (IP; b), decreased precipitation (DP; $\mathbf{c}), \mathrm{eCO}_{2}(\mathbf{d})$ and eN $(\mathbf{e})$. f $\mathbf{f}$ h, The changes in rootto-shoot ratios $(\triangle R / S)$ under individual global change drivers, and the changes in carbon-cycle variables under normalized IP (NIP, a $33 \%$ precipitation increase) and $\mathrm{eCO}_{2}$ for different ecosystems, respectively. $\mathbf{i}$, The changes in $\mathrm{AGB}, \mathrm{RB}$, soil $\mathrm{pH}$ and $\mathrm{SR}$ under different eN rates. Significant $(P<0.05) Q_{B}$ (between-group heterogeneity) indicates that the response ratios differ among ecosystems $(\mathbf{g}, \mathbf{h})$ or eN rates (i). The sample sizes are given along the $y$ axis. The vertical dashed lines are zero lines. See Fig. 1 for abbreviations.

were more sensitive to increased than to decreased precipitation across all ecosystems (Table 1). The results generalize previous observations on ANPP responses to inter-annual rainfall variation at the Long Term Ecological Research Network sites ${ }^{26}$ to all the carbon-cycle processes analysed here and the larger range of precipitation changes applied in manipulative experiments. All these findings indicate that most terrestrial ecosystems have resistance to drought, which might arise from intrinsic plant physiological adaptation, enhanced water-use efficiency and/or shifts in plant community composition ${ }^{5,26,29-31}$. Increased mortality and decreased vegetation cover in response to water stress under decreased precipitation could help to explain the greater sensitivity of litter mass to decreased rather than increased precipitation. These patterns indicate a temporary mismatch of litter mass and aboveground net primary productivity in response to reduced precipitation, highlighting the non-uniform influences of precipitation anomalies on different carbon-cycle variables and the large variability in the analysed studies ${ }^{27}$, precluding specific interpretations. The potential disconnection between production and decomposition processes also suggests avenues for future comparative research, which would reveal novel mechanisms for ecosystem carbon cycling. Furthermore, the sensitivities of gross ecosystem productivity and ecosystem respiration to changing precipitation were generally greater than those of plant productivity, biomass and litter mass.

The greater sensitivity of aboveground than belowground net primary productivity in response to increased precipitation suggests that plants invest less carbon in water acquisition structures when relieved from water stress (Table 1), leading to reduced root-to-shoot ratios (Fig. 2f). Our observations are supported by the finding from a previous review revealing greater carbon allocation to aboveground wood production than to belowground carbon fluxes in forest ecosystems in response to increasing resource (for example, water and nutrient) supply ${ }^{32}$. In contrast, the enhanced root-to-shoot ratios under decreased precipitation indicate that plants allocate more carbon to water- and nutrientacquiring structures to resist drought, and thus there is a higher sensitivity of above- (aboveground net primary productivity and biomass, and litter mass) than belowground carbon-cycle variables 
a

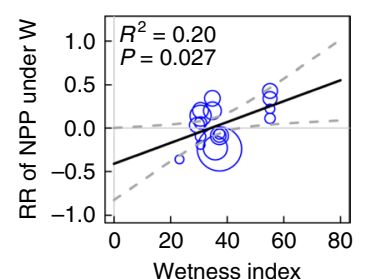

e

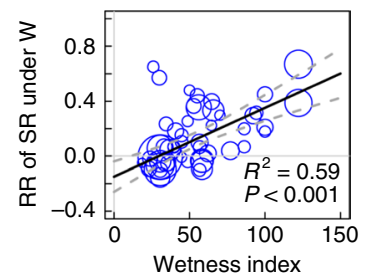

i
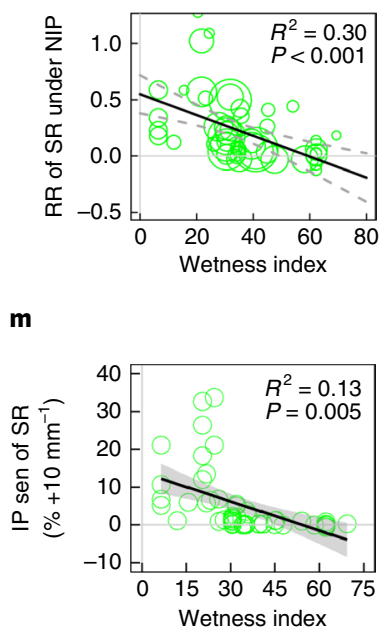

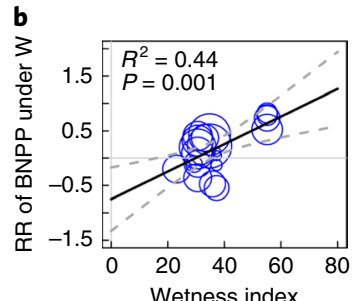

c
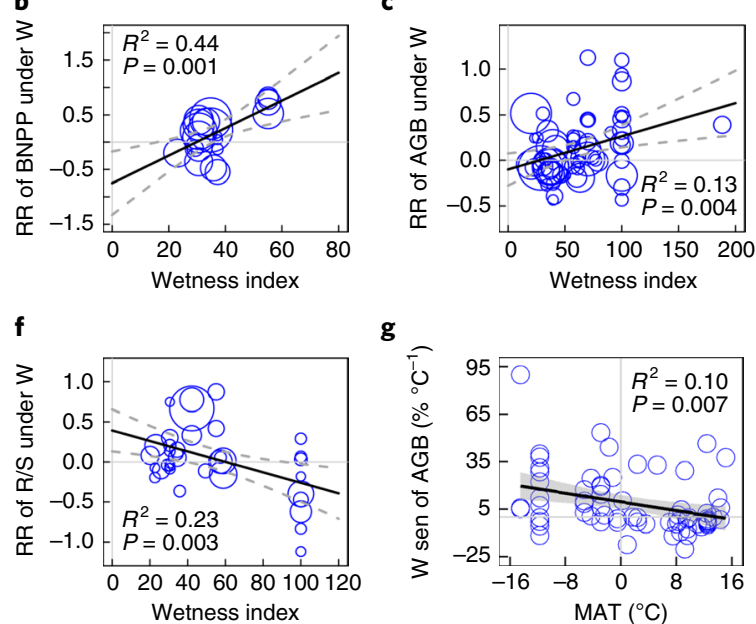

k

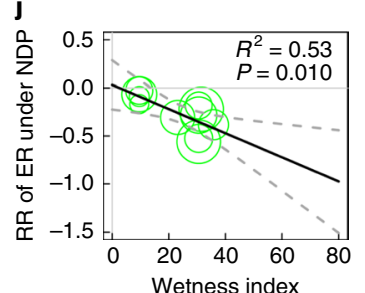

n

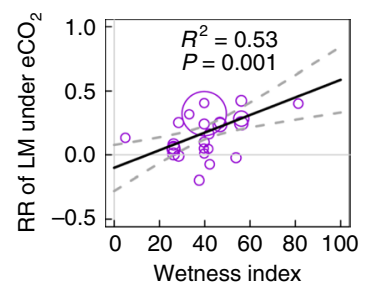

\section{要}

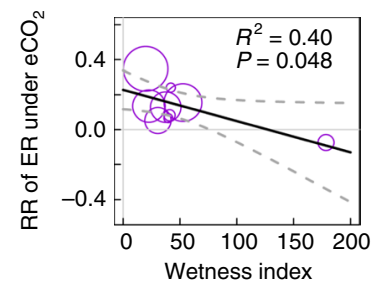

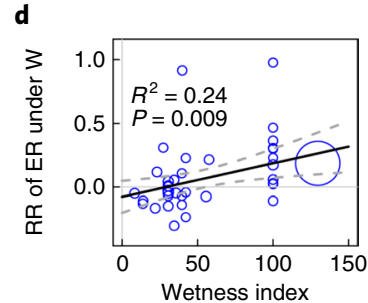

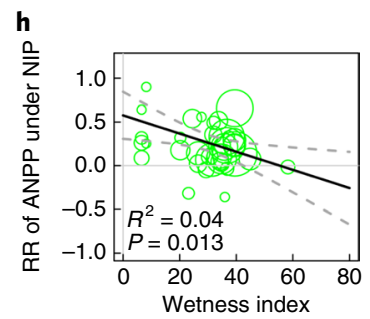

I

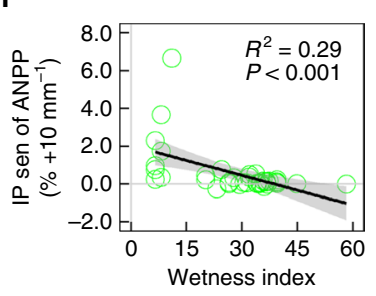

p

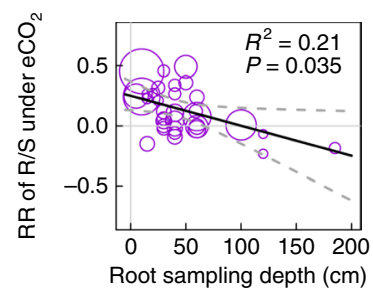

Fig. 3 | Local climate conditions and plant traits affecting carbon-cycle responses to global change drivers. a-f, $\mathbf{h}-\mathbf{j}, \mathbf{n}-\mathbf{p}$, Bubble plots of the metaregression results between the response ratio (RR) of NPP (a), BNPP (b), AGB (c), ER (d), SR (e) and R/S (f) under W and the wetness indices, between the RR of ANPP (h) and SR (i) under NIP and the wetness indices, between the RR of ER ( $\mathbf{j})$ under normalized DP (NDP) and the wetness indices, between the RR of litter mass $(\mathbf{n})$ and $\mathrm{ER}(\mathbf{o})$ under $\mathrm{eCO}_{2}$ and the wetness indices, and between the RR of R/S under e $\mathrm{CO}_{2}$ and root sampling depths (p). Linear meta-regressions are shown as black solid lines and grey dashed lines represent $95 \% \mathrm{Cls}$. g,k-m, Single linear regressions showing dependences of $\mathrm{W}$ sensitivity (sen) of AGB on mean annual temperature (MAT; $\mathbf{g}$ ), and of IP sen of NPP ( $\mathbf{k})$, ANPP (I) and SR ( $\mathbf{m}$ ) on the wetness indices. Linear regression is shown as a black solid line and $95 \% \mathrm{Cls}$ are in the shaded area. Each point represents the effect size of an individual study. Greater wetness index values correspond to more humid climate conditions. See Figs. 1 and 2 for abbreviations.

\section{Table 1 | Relative sensitivity of ecosystem carbon-cycle variables in response to global change drivers}

\begin{tabular}{lllllll} 
& & W & IP & DP & eCO & eN \\
\hline Whole-plant & NPP & $-7.2[-30.8,16.5]$ & $1.5[0.7,2.3]$ & $-1.1[-2.3,0.1]$ & $7.8[1.4,14.2]$ & $1.3[0.6,2.1]$ \\
& TB & $16.4[2.5,30.2]$ & $2.1[-0.1,4.3]$ & $-1.0[-2.4,0.3]$ & $11.7[8.1,15.2]$ & $5.5[3.1,7.9]$ \\
Aboveground & ANPP & $-1.9[-13.2,9.5]$ & $5.4[1.5,9.3]$ & $-1.7[-3.0,-0.3]$ & $13.0[6.1,19.9]$ & $4.0[1.5,6.5]$ \\
& AGB & $9.2[4.4,14.1]$ & $1.9[0.6,3.2]$ & $-1.0[-1.7,-0.3]$ & $8.2[5.9,10.6]^{102}$ & $4.0[3.1,4.9]^{206}$ \\
& Litter & $1.4[-12.4,15.2]$ & $-0.02[-0.9,0.8]$ & $-2.0[-3.7,-0.2]$ & $8.7[4.2,13.1]$ & $7.2[2.0,12.4]$ \\
Belowground & BNPP & $7.1[-20.9,35.0]$ & $2.0[-0.4,4.5]$ & $-1.6[-2.5,-0.7]$ & $23.6[12.9,34.3]$ & $1.5[-1.5,4.6]$ \\
& RB & $19.8[-1.9,41.4]$ & $2.1[-0.01,4.1]$ & $-0.3[-1.2,0.6]$ & $17.9[10.6,25.1]^{98}$ & $3.1[1.6,4.7]$ \\
& SR & $5.0[0.4,9.6]$ & $8.4[3.8,12.9]$ & $-1.1[-1.5,-0.7]$ & $15.1[10.6,19.6]$ & $0.6[-1.1,2.2]^{91}$ \\
Carbon fluxes & GEP & $8.9[-3.6,21.3]$ & $8.0[2.1,13.9]$ & $-2.0[-2.5,-1.6]$ & $5.0[1.2,8.8]$ & $41.5[-14.2,97.2]$ \\
& ER & $10.8[1.9,19.6]$ & $5.9[2.1,9.7]$ & $-2.4[-3.6,-1.2]$ & $7.7[1.6,13.7]$ & $25.6[-4.9,56.2]$ \\
\hline
\end{tabular}

The weighted mean sensitivity (means $[-95 \% \mathrm{Cl}+95 \% \mathrm{CI}]^{\text {sample size }}$ ) of whole-plant production (NPP and TB), aboveground (ANPP, AGB and LM) and belowground carbon-cycle variables (BNPP, RB and $\mathrm{SR}$ ), and ecosystem carbon fluxes (GEP and ER) under W $\left(\%+1^{\circ} \mathrm{C}-1\right), I P\left(\%+10 \mathrm{~mm}^{-1}\right), \mathrm{DP}\left(\%-10 \mathrm{~mm}^{-1}\right), \mathrm{eCO}_{2}\left(\%+100 \mathrm{ppm}^{-1}\right)$ and eN $\left(\%+1 \mathrm{~g} \mathrm{~N} \mathrm{~m}{ }^{-2} \mathrm{yr}^{-1}\right)$ across all the manipulative experiments. See Figs. 1 and 2 for abbreviations. 
(belowground net primary productivity, root biomass and soil respiration) under decreased precipitation (Table 1). However, a previous study on carbon allocation of 14 mature forest stands has found a decreased root-to-leaf biomass ratio under drought, largely due to accelerated root turnover in a drier climate ${ }^{33}$. Therefore, it should be noted that changing precipitation regimes may have differential effects on carbon cycling, depending on other local climate conditions (for example, existing moisture conditions and precipitation timing and intensity). For example, precipitation increase at a dry or mesic site could stimulate biological activity, as opposed to a moist site where responses may be neutral and even negative $e^{6,27,34,35}$. Our observations that the sensitivities of net primary productivity (Fig. $3 \mathrm{k} ; R^{2}=0.19, P=0.042$ ) and its aboveground component (Fig. 31; $R^{2}=0.29, P<0.001$ ), and soil respiration (Fig. $3 \mathrm{~m} ; R^{2}=0.13$, $P=0.005)$ to increased precipitation shifted from positive to negative with increasing wetness indices provided direct evidence supporting this conclusion. Nevertheless, caution should be taken when extrapolating our findings to generate regional and global effects of changing precipitation amount, because rainfall frequency and intensity may be potentially important confounding factors in this meta-analysis.

\section{More carbon allocated to plant belowground tissues under $\mathrm{eCO}_{2}$}

This synthesis demonstrated that, despite large variations among ecosystems, $\mathrm{eCO}_{2}$ significantly stimulated plant productivity, biomass, litter mass and ecosystem carbon fluxes, with the exception of net ecosystem productivity which appeared highly uncertain (Fig. 2d). The observations could have been primarily attributed to increased leaf photosynthesis and water-use efficiency associated with $\mathrm{CO}_{2}$ fertilization effects and water-saving mechanisms under $\mathrm{eCO}_{2}$ (for example, decreased stomatal conductance and consequent evapotranspiration $)^{36}$. We expected $\left(\mathrm{H}_{3}\right)$ that positive $\mathrm{eCO}_{2}$ effects would be greater in drier than humid ecosystems ${ }^{37,38}$ because enhanced water-use efficiency under $\mathrm{eCO}_{2}$ would benefit plants especially under water limitation. However, results of meta-regressions to explore the correlations of the $\mathrm{eCO}_{2}$ effects with mean annual precipitation and wetness indices showed no clear trends of the 12 carbon-cycle variables along mean annual precipitation. Higher wetness did not affect most of the carbon-cycle variables either, but was associated with a larger $\mathrm{eCO}_{2}$ effect on litter mass (Fig. 3n; $R^{2}=0.53$, $P=0.001$ ), contradicting our hypothesis $\mathrm{H}_{3}$. Nevertheless, ecosystem respiration responses to $\mathrm{eCO}_{2}$ significantly declined with increasing wetness indices (Fig. 30; $R^{2}=0.40, P=0.048$ ), partly supporting our hypothesis $\mathrm{H}_{3}$. These observations suggest that $\mathrm{CO}_{2}$ fertilization effects may be mediated by not only wetness expressed with a simple average index, but also other factors such as precipitation seasonal distributions ${ }^{39,40}$ and extreme climate events ${ }^{41}$.

Further analyses indicate that ecosystem type also explains a fraction of variations in the $\mathrm{eCO}_{2}$ effects among sites. For example, grasslands with low net primary productivity and aboveground biomass responded more weakly to $\mathrm{eCO}_{2}$ than forests (Fig. $2 \mathrm{~h}$ ). The stronger responses of forests may be attributable to the fact that the 'forests' label in our analyses included tree seedlings with exponential growth over multiple growing seasons, which can greatly exaggerate the responses of older trees in a linear growth phase ${ }^{42}$. In addition, different mycorrhizal types associated with temperate forests, grasslands and tundra may help to explain variations among ecosystems in the response to $\mathrm{eCO}_{2}{ }^{43}$. Unfortunately, mycorrhizal information was not reported in most studies.

Based on statistically significant changes in carbon-cycle variables under $\mathrm{eCO}_{2}$ (Fig. 2d), we calculated the $\mathrm{eCO}_{2}$ sensitivity as percentage change per $100 \mathrm{ppm} \mathrm{CO}_{2}$ increase ${ }^{44}$. Across all $\mathrm{eCO}_{2}$ experiments, gross ecosystem productivity and net primary productivity showed strongly positive $\mathrm{CO}_{2}$ sensitivity (Table 1 ). Plants under $\mathrm{eCO}_{2}$ allocated more carbon to roots for uptake of water and
$\mathrm{N}$ for sustaining growth, at least in young forest/seedling experiments where an increase in plant root-to-shoot ratios was observed across ecosystems (Fig. 2f) - an observation supported by findings of a previous meta-analysis ${ }^{45}$. Nevertheless, another experimental study has demonstrated that enhanced root carbon allocation in a high $\mathrm{CO}_{2}$ atmosphere generally occurs in a field (free-air $\mathrm{CO}_{2}$ enrichment) but not in a controlled (growth chamber) environment ${ }^{46}$. In addition, we found that the positive effects of $\mathrm{eCO}_{2}$ on root-to-shoot ratios declined with increasing depths of root sampling (Fig. 3p; $R^{2}=0.21, P=0.035$ ) - a result more consistent with the proliferation of shallow fine roots for harvesting nutrients rather than of deep roots for water uptake $e^{47}$. In contrast, a previous synthesis on forest ecosystems has revealed that $\mathrm{eCO}_{2}$ stimulates root proliferation in deep soil, likely because the limited resource of topsoil cannot meet the increased demand for production enhancements under $\mathrm{CO}_{2}$ enrichment ${ }^{48}$. Given that the depths of root sampling are usually greater in forests than grasslands, these observations suggest that root-to-shoot ratios may respond to $\mathrm{eCO}_{2}$ more strongly in grasslands than forests, as shown by our meta-analysis results (Fig. 2h; $Q_{B}=5.70, P=0.02$ ). Similar to the observed increases in gross ecosystem productivity, ecosystem and soil respiration were also enhanced under $\mathrm{eCO}_{2}$, indicating that $\mathrm{eCO}_{2}$ accelerates ecosystem carbon turnover through belowground processes (for example, microbial decomposition and soil $\mathrm{CO}_{2}$ efflux ${ }^{49-51}$. Root exudation and possibly root litter and organic matter decomposition might be stimulated under $\mathrm{eCO}_{2}$, thus a considerable fraction of increased net primary productivity is in fast-turnover pools that do not lead to carbon sequestration but are released back to the atmosphere. The coupling between net primary productivity and heterotrophic respiration under $\mathrm{eCO}_{2}$ likely depends on the experimental duration. Under long-term exposure to $\mathrm{eCO}_{2}$, the two processes are expected to be closely coupled and net ecosystem productivity should approach zero after a new equilibrium is reached ${ }^{52}$, although none of the experiments were long enough to verify this assumption.

\section{More carbon allocated to plant aboveground than belowground tissues under $\mathbf{N}$ addition}

Nitrogen addition significantly stimulated plant productivity, biomass, litter mass and ecosystem carbon fluxes, but not belowground net primary productivity or net ecosystem productivity (Fig. 2e). In contrast, $\mathrm{N}$ addition reduced soil respiration across all the experiments assessed. Presumably, $\mathrm{N}$ availability limits net primary productivity in many ecosystems ${ }^{53}$. In contrast to the effects of $\mathrm{eCO}_{2}$, more carbon appeared to be allocated to above- than belowground tissues under $\mathrm{N}$ addition. Decreased root-to-shoot ratios in response to $\mathrm{N}$ addition across ecosystems suggest that the sensitivities of aboveground carbon-cycle variables to $\mathrm{N}$ addition are higher than those of belowground carbon-cycle variables (Fig. $2 \mathrm{f}$ and Table 1). The results are consistent with the general observations that plants invest less carbon in constructing nutrient-acquiring structures (that is, roots) when more nutrients are available ${ }^{32,54-56}$. Our findings of substantial variability of plant carbon allocation in responses to different global change drivers are critical in evaluating Earth system models ${ }^{57,58}$.

The large number of $\mathrm{N}$ addition experiments compiled in this study (429) provides a unique opportunity to further analyse the effects of $\mathrm{N}$ addition on aboveground biomass, root biomass and soil respiration. Aboveground biomass increased with increasing levels of $\mathrm{N}$ addition rates $\left(\leq 5,5-10\right.$ and $>10 \mathrm{~g} \mathrm{~N} \mathrm{~m}^{-2} \mathrm{yr}^{-1}$; Fig. $2 \mathrm{i} ; Q_{\mathrm{B}}=7.20$, $P=0.03)$. The stimulation of aboveground biomass was greater at $\mathrm{N}$ addition rates $>10 \mathrm{~g} \mathrm{~N} \mathrm{~m}^{-2} \mathrm{yr}^{-1}$ (32.1\%) than $\leq 5 \mathrm{~g} \mathrm{~N} \mathrm{~m}^{-2} \mathrm{yr}^{-1}$ (13.6\%). However, there was no difference in root biomass responses among the three $\mathrm{N}$ addition levels, likely due to the lower sensitivity of below- than aboveground biomass and productivity in response to $\mathrm{N}$ addition (Table 1). By contrast, soil respiration did not respond to the low or medium levels of $\mathrm{N}$ addition but decreased by $10.2 \%$ at 
the high $\mathrm{N}$ addition rates of $>10 \mathrm{~g} \mathrm{~N} \mathrm{~m}^{-2} \mathrm{yr}^{-1}$, which is partly inconsistent with the findings of a previous meta-analysis that both low $(<5)$ and high $(>5) \mathrm{N} \mathrm{m}^{-2} \mathrm{yr}^{-1}$ additions suppressed soil $\mathrm{CO}_{2}$ efflux in forest ecosystems ${ }^{54}$. The inclusion of grasslands and tundra in this study makes the conclusions more convincing. High $\mathrm{N}$ addition rates may reduce soil heterotrophic respiration due to acidificationinduced reduction in microbial activity, and thus suppress soil respiration $^{54,59}$. Indeed, the decrease in soil $\mathrm{pH}$ was exacerbated with higher rates of $\mathrm{N}$ addition (Fig. 2i). Clearly, $\mathrm{N}$ addition rate is criti$\mathrm{cal}$ in estimating ecosystem carbon-cycle responses to atmospheric $\mathrm{N}$ deposition. Yet, given that manipulative experiments generally imposed greater amounts of $\mathrm{N}$ than the current global mean rates of atmospheric $\mathrm{N}$ deposition (Fig. 1e), the responses of ecosystem carbon cycling in these experiments are likely stronger than those caused by the forecasted levels of atmospheric $\mathrm{N}$ deposition.

\section{Nonlinear effects of two-driver pairs were rare}

Under current and future conditions, ecosystems will be exposed to concurrently multiple global change drivers (Fig. 1b-e). Nonlinear effects of co-occurring drivers pose challenges for understanding and projecting terrestrial carbon-climate feedbacks ${ }^{8}$. Two previous syntheses demonstrated that multiplicative influences were rare and ecosystem responses declined with increasing numbers of manipulated factors $^{60,61}$, suggesting that antagonistic mechanisms are widespread when global change drivers are altered simultaneously. In contrast, other meta-analyses found that multiplicative, rather than synergistic or antagonistic, effects on woody plant biomass, ecosystem carbon storage and soil $\mathrm{CO}_{2}$ efflux were more common ${ }^{62-64}$. These contrasting conclusions leave model predictions of such interactions in question $^{60}$, especially given that three- and four-factor studies are too scarce to draw general conclusions. We analysed data from 80 twofactor experiments to examine whether the influence of one driver on carbon-cycle variables was modified by a second driver.

Our results showed that nonlinear effects (that is, synergistic or antagonistic) of two-driver pairs-including warming and increased precipitation, warming and decreased precipitation, warming and $\mathrm{eCO}_{2}$, warming and $\mathrm{N}$ addition, increased precipitation and $\mathrm{N}$ addition, decreased precipitation and $\mathrm{eCO}_{2}$, as well as $\mathrm{eCO}_{2}$ and $\mathrm{N}$ addition-on all carbon-cycle variables were rare (Fig. $4 \mathrm{a}-\mathrm{g}$ ). These observations differ from the findings of Leuzinger et al. ${ }^{60}$ and Dieleman et al. ${ }^{61}$-a discrepancy that probably resulted from the different analytical methods. For example, Dieleman et al. ${ }^{61}$ assessed interactions between warming and $\mathrm{eCO}_{2}$ on plant biomass and soil process variables (for example, soil respiration, soil carbon content and net $\mathrm{N}$ mineralization) by comparing the slopes of the linear correlations of the combined warming and $\mathrm{eCO}_{2}$ influences with the sum of individual effects with 1:1 line. Leuzinger et al. ${ }^{60}$ pooled plant biomass and soil process variables together to explore the differences in the response magnitudes under one, two and three global change drivers. When compared with the two previous reviews using Hedges' $d$ method that concluded predominantly multiplicative effects on ecosystem carbon storage and soil $\mathrm{CO}_{2}$ emissions $^{63,64}$, our results, obtained with different analytical methods and database, confirm that the nonlinear effects of multiple global change drivers on the carbon-cycle processes analysed are relatively infrequent. Another study using the same methodological approach as ours found that warming and $\mathrm{eCO}_{2}$ multiplicatively affected aboveground biomass of woody plants ${ }^{62}$, further supporting our conclusion. Moreover, a most recent study reporting a fourfactor (temperature, precipitation, $\mathrm{CO}_{2}$ and $\mathrm{N}$ ) experiment revealed predominantly multiplicative influences among the four global change drivers on ecosystem carbon cycling in a temperate grassland $^{51}$, providing other lines of supporting evidence. All the above findings indicate that changes in carbon-cycle variables under multiple global change drivers can be under- or overestimated if more antagonistic ${ }^{60,61,65}$ or synergistic ${ }^{44,66}$ effects are assumed.
Nevertheless, two experimental studies on $\mathrm{N}$ cycling and net primary productivity by manipulating three ${ }^{65}$ and four ${ }^{67}$ factors demonstrated that the majority of interactions among multiple factors are antagonistic rather than multiplicative or synergistic, thereby dampening the net effects. From a global perspective, more direct evidence on whether multiplicative effects among global change drivers hold for experimental studies manipulating three or four factors is crucial for convincing projections of future global change terrestrial carbon-cycling feedbacks.

\section{The future of global change manipulative experiments}

During the past two decades, meta-analyses have reported ecosystem carbon-cycle responses to warming ${ }^{2,4,5,68,69}$, changing precipitation amount ${ }^{5,23}, \mathrm{eCO}_{2}$ (refs. ${ }^{1,45,70-73}$ ) and $\mathrm{N}$ addition ${ }^{3,54,73,74}$, but relatively few have examined the combined effects (but see refs. ${ }^{61-64}$ ). The data synthesis presented in this study, encompassing all global change manipulative experiments published to date, revealed global-scale general patterns of the responses and sensitivity of all the terrestrial carbon-cycle processes to multiple global change drivers and their interactions. Further discussion on the discrepancy between our findings and those from previous meta-analyses is provided in Supplementary Text 2. In addition, sensitivity analyses were developed to inform model validation, thus caution should be taken when using our findings to predict the impact magnitudes of global change drivers on carbon-cycle variables at given experiments (Supplementary Fig. 5). While global change research has made tremendous progress in developing manipulative experiments to better simulate climate change scenarios ${ }^{7,75}$, our synthesis highlights three key issues that need to be addressed in future experimental studies to better facilitate and assess model projection on terrestrial carbon cycling and its feedback to climate change.

First, although the existing manipulative experiments are critical to understand and disentangle mechanisms (for example, ref. ${ }^{76}$ ), identify thresholds and tipping points of ecosystem responses to global change drivers ${ }^{77}$, and provide necessary information (input data and process understanding) for the modelling community ${ }^{11}$, the majority of the experiments have done a poor job of simulating the more complex climate change scenarios. For example, the stochastic nature of precipitation events causes substantial uncertainty in predicting future scenarios and great challenges in designing experiments to capture the full breadth of possibilities inherent in these scenarios. This is made even more difficult if experiments also attempt to capture the impacts of extreme events and exceeded thresholds ${ }^{6,7,78-80}$

Second, the majority of existing studies focused on single-factor effects and thus precluded the analysis of nonlinear influences on carbon-cycle feedbacks among multiple global change drivers ${ }^{8}$. Although the combined treatment effects of two-driver pairs on carbon cycling were mostly multiplicative (Fig. 4), three- and fourfactor experiments are still urgently needed to generate multidimensional (that is, multiple factors) response surfaces for carbon-cycle variables aiming to accurately quantify terrestrial carbon-global change feedbacks ${ }^{81}$. More specifically, changing plant community composition over a long-term scale may also lead to the occurrence of nonlinear effects among multiple factors ${ }^{82,83}$, indicating the importance of plant competition in regulating ecosystem responses to concurrent global change drivers ${ }^{30}$.

Finally, the influences of global change on carbon cycling are ecosystem- and climate-specific, suggesting that more experimental data from several hotspot regions are necessary to improve the global perspective. Semi-arid regions, forest ecosystems in the subtropics and tropics, and Arctic tundra are underrepresented in experiments, although they store large quantities of organic carbon and thus have a disproportionate impact on global carboncycling and climate change-carbon feedbacks (Fig. 1a) ${ }^{6,13-15}$. In sum, forecasting terrestrial carbon-cycle responses to ongoing global 

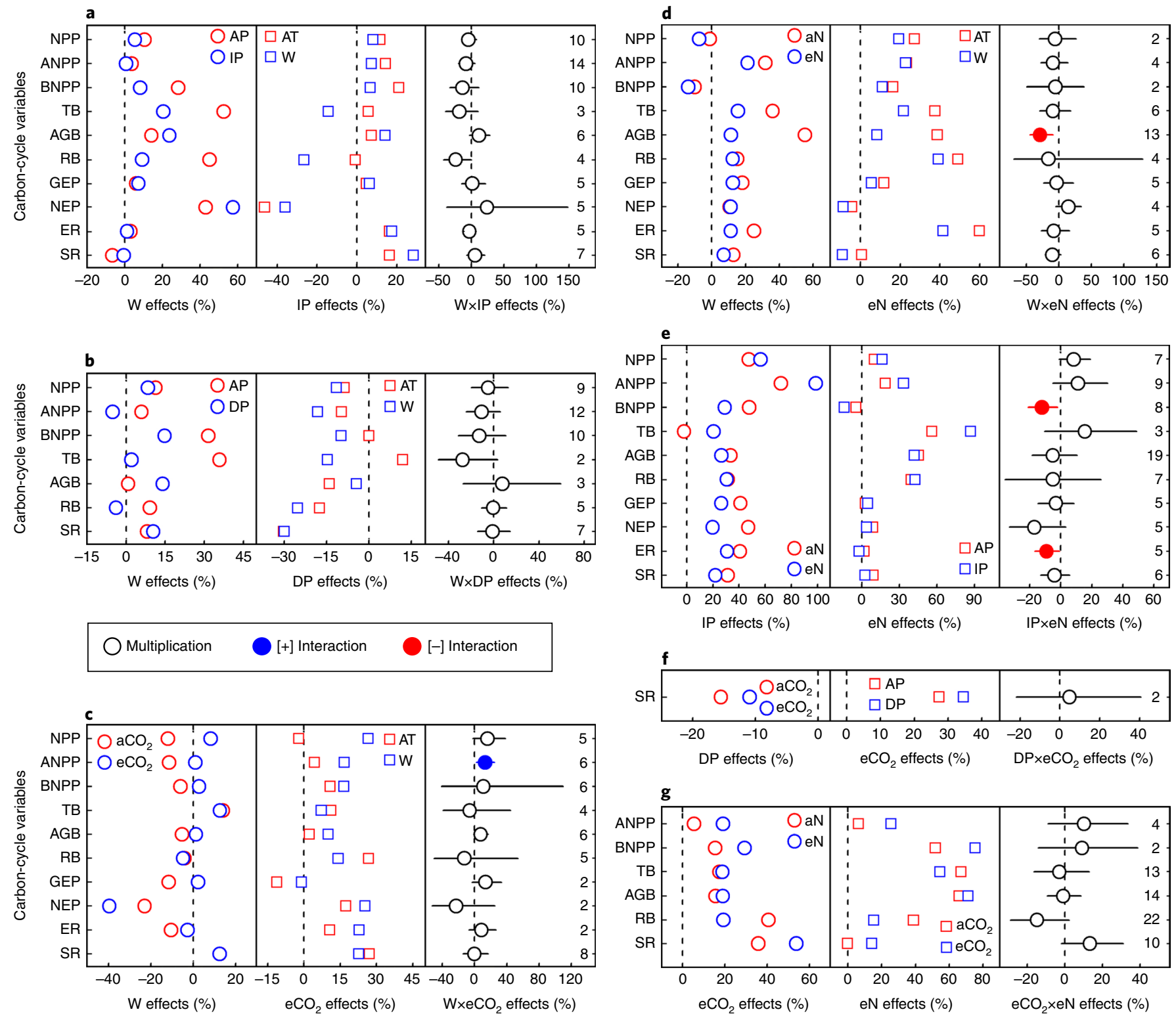

Fig. 4 | Interaction types of two-driver pairs. a-g, Forest plots on the effect sizes (means $\pm 95 \% \mathrm{Cls}$ ) of the interaction terms including $\mathrm{W} \times \mathrm{IP}(\mathbf{a}), \mathrm{W} \times \mathrm{DP}$ (b), $\mathrm{W} \times \mathrm{eCO}_{2}(\mathbf{c}), \mathrm{W} \times \mathrm{eN}(\mathbf{d}), \mathrm{IP} \times \mathrm{eN}(\mathbf{e}), \mathrm{DP} \times \mathrm{eCO}_{2}(\mathbf{f})$ and $\mathrm{eCO}_{2} \times \mathrm{eN}(\mathbf{g})$. The sample sizes are given along the $y$ axis. The vertical dashed lines are zero lines. If the $95 \% \mathrm{Cls}$ overlapped with zero, the interactive effects across experiments were considered to be multiplicative (open black circles), otherwise the interactive effects were positive (filled blue circles) or negative interactions (filled red circles). See Figs. 1 and 2 for abbreviations. (AT, ambient temperature; $\mathrm{AP}$, ambient precipitation; $\mathrm{aCO}_{2}$, ambient $\mathrm{CO}_{2} ; \mathrm{aN}$, ambient $\mathrm{N}$ deposition.)

change requires future manipulative experiments aiming at knowledge useful to inform mechanistic models (for example, gradient treatments) ${ }^{84}$, to include multiple driving factors, and to focus on underrepresented arid/semi-arid, subtropical/tropical and tundra ecosystems.

\section{Methods}

Data compilation and analysis. Peer-reviewed publications that reported ecosystem manipulative experiments in global change research were collected by searching Web of Science (WoS; 1 January 1900 to 13 December 2016) to construct the dataset of the synthesis during January-May 2017. Databases used for the search in WoS included (1) WoS Core Collection, (2) Inspec, (3) KCIKorean Journal Database, (4) BIOSIS Previews, (5) Derwent Innovations Index, (6) Russian Science Citation Index, (7) Data Citation Index, (8) Chinese Science Citation Database, (9) MEDLINE and (10) SciELO Citation Index. Global change drivers considered were climate warming $(\mathrm{W})$, changing precipitation regimes
$(\mathrm{P})$, atmospheric $\mathrm{CO}_{2}$ enrichment $\left(\mathrm{eCO}_{2}\right)$, enriched atmospheric nitrogen $(\mathrm{N})$ deposition (eN), and their combinations, including WP, $\mathrm{WeCO}_{2}, \mathrm{WeN}, \mathrm{PeCO}_{2}$ $\mathrm{PeN}, \mathrm{eCO}_{2} \mathrm{eN}, \mathrm{WPeCO}_{2}, \mathrm{WPeN}, \mathrm{PeCO}_{2} \mathrm{eN}$ and $\mathrm{WPeCO}_{2} \mathrm{eN}$. Therefore, the keywords for title search used in WoS were: (1) global change (13,053 records), (2) climate change (49,540 records), (3) free-air carbon dioxide enrichment ( 88 records), (4) free-air $\mathrm{CO}_{2}$ enrichment (282 records), (5) elevated carbon dioxide (1,228 records), (6) elevated $\mathrm{CO}_{2}$ (4,169 records), (7) elevated atmospheric $\mathrm{CO}_{2}$ (681 records), (8) $\mathrm{CO}_{2}$ enrichment (1,274 records), (9) $\mathrm{eCO}_{2}$ (14 records), (10) $\left[\mathrm{CO}_{2}\right](113,089$ records), (11) warming (90,699 records), (12) elevated temperature (18,336 records), (13) changing precipitation (2,433 records), (14) increased precipitation (434 records), (15) decreased precipitation (93 records), (16) nitrogen deposition (3,777 records), (17) nitrogen addition (2,367 records) and (18) nitrogen application $(8,620$ records).

First, we identified publications from all 310,177 records through reading each title. In this step, we excluded 202,257 records whose titles showed that these studies were reviews/meta-analyses or conducted in non-terrestrial ecosystems (for example, oceans; Supplementary Fig. 6). The remaining 107,920 publications that might be 
relevant to our topic were included. Second, we further screened publications that may have reported global change effects on terrestrial ecosystems by reading the abstracts of all the 107,920 publications collected in the first step. Similar to the first step, we excluded 89,179 publications whose abstracts indicated that these studies were reviews/meta-analyses or conducted in non-terrestrial ecosystems. The PDF versions of the remaining 18,741 publications that might be relevant to the synthesis were downloaded. Third, we selected publications by reading the methods of the 18,741 studies to identify which of them met the following inclusion criteria:

- Studies reported results of manipulative experiments conducted in the outdoor environment and having both control and treatment groups. Each group had at least three plots as replicates. In addition, the area of each plot was larger than $1 \mathrm{~m}^{2}$. The treatment groups were manipulated artificially to simulate global change drivers. For example, grassland plots of treatment groups were warmed using infrared radiators ${ }^{51}$

- Experiments were conducted in terrestrial ecosystems. However, cropland and lab incubation studies were not included in this synthesis.

- Studies examined effects of simulated global change drivers on ecological processes, including carbon (for example, net primary productivity and its above- and belowground components, total, aboveground and root biomass, root-to-shoot ratios, litter mass, gross and net ecosystem productivity, and ecosystem and soil respiration, and so on), nitrogen (for example, soil N content and $\mathrm{N}$ mineralization rates) and water-cycle variables (for example, evapotranspiration and water-use efficiency) as well as plant (for example, plant cover, species richness and community temporal stability) and microbia parameters (for example, microbial biomass and microbial community composition and structure).

In the third step, we excluded 17,451 publications which did not meet the above inclusion criteria. After screening this huge number of publications, 1,290 studies met the defined criteria. This list of 1,290 publications was subsequently cross-checked with references cited in the previous review/meta-analysis articles that studied global change influences on ecological processes, as well as publications used in this list to ensure that our publication survey was as inclusive as possible, and 756 additional publications were found. Finally, by searching the websites of ecology laboratories and experiment networks-for example, http:// www2.nau.edu/luo-lab/, https://mnspruce.ornl.gov/, http://www.nutnet.org/, https://www.ars.usda.gov/plains-area/fort-collins-co/center-for-agriculturalresources-research/rangeland-resources-systems-research/docs/range/prairieheating-and-co2-enrichment-phace-experiment/research/, http://www.biocon. umn.edu/, http://www.utas.edu.au/profiles/staff/plant-science/Mark-Hovenden and http://web.ics.purdue.edu/ jsdukes/Dukes.html—and checking the references of the papers downloaded from these websites, another 184 studies were collected. In total, 2,230 publications were included in the synthesis.

Information including publication year, simulated global change drivers, experimental duration, site locations and altitudes, site climate conditions (mean annual temperature (MAT) and precipitation (MAP)), vegetation types and the manipulation magnitudes of global change drivers was extracted from each of the 2,230 publications collected in our literature search to demonstrate the state-ofthe-art and analyse the future challenges of ecosystem manipulative experiments in global change research. Based on this information, the 2,230 publications were classified into two groups: (1) publications reporting single-factor experiments having a single control and at least one single-factor treatment (for example, $\mathrm{eCO}_{2}$ or $\mathrm{eN}$ ) and (2) publications reporting multifactor experiments using factorial designs having a single control, multiple single-factor treatments (for example, $\mathrm{eCO}_{2}$ and $\mathrm{eN}$ ), and combinations of factors (for example, $\mathrm{eCO}_{2}+\mathrm{eN}$ ). In addition, we identified how many single- and multifactor experiments were documented in the 2,230 publications. If a publication reported several experiments conducted at different sites or in different plant communities, it would be considered as several independent experiments. If a single-factor experiment manipulated several different global change drivers with a same control at the same site, it would be broken up into several independent control-treatment pairs and thus considered as several independent experiments. Values of MAT and MAP were downloaded from Climate Model Intercomparison Project phase 5 (CMIP5; https://esgf-node.llnl. gov/projects/cmip5/) based on the site locations if individual studies did not report these values for their sites. Ecosystems subjected to manipulative experiments were classified into five typical types: forests (including mature forests and tree seedlings), grasslands (including grasslands, meadows, short- and tall-grass prairies, temperate/semi-arid steppes, shrublands, savannas, pastures and oldfields), tundra, wetlands (including peatlands, bogs, marshes and fens) and deserts. In this study, $86.5 \%$ and $59.6 \%$ of single- and multifactor forest experiments were conducted in mature forests, respectively.

We plotted the distributions of MAT and MAP against latitude, and calculated the De Martonne wetness index ${ }^{85}$ of each experimental site using the data of MAT and MAP as

$$
\text { Wetness index }=\frac{\text { MAP }}{\text { MAT }+10}
$$

In addition, the spatial distributions of single- and multifactor experiments were mapped in ArcMAP v.10.0. Moreover, to compare the differences between the manipulation magnitudes of global change drivers extracted from the 2,230 publications and realistic climate change scenarios, we calculated the changes in MAT, MAP and atmospheric $\mathrm{CO}_{2}$ concentrations at each experimental site as the differences between the periods of 2081-2100 and 1986-2005 using the data reported in the IPCC RCP2.6, 4.5, 6.0 and 8.5. Maximum average $\mathrm{N}$ deposition over the world projected in RCP2.6 $\left(1.55 \mathrm{~g} \mathrm{~N} \mathrm{~m}^{-2} \mathrm{yr}^{-1}\right)$, RCP4.5 $\left(1.02 \mathrm{~g} \mathrm{~N} \mathrm{~m}^{-2} \mathrm{yr}^{-1}\right)$ and RCP8.5 $\left(1.32 \mathrm{~g} \mathrm{~N} \mathrm{~m}^{-2} \mathrm{yr}^{-1}\right)$ by the end of the twenty-first century used in the synthesis were reported in Lamarque et al. ${ }^{17}$.

Effects of individual global change drivers on ecosystem carbon-cycle variables: meta-analysis. This study focused on the responses of ecosystem carbon cycling to global change drivers. Data of mean values $(\bar{X})$, standard deviations (s.d.) or standard errors (s.e.m.) and sample sizes (number of plot replication) of ecosystem carbon-cycle variables (net primary productivity and its above- and belowground components, total, aboveground and root biomass, root-to-shoot ratios, litter mass, gross and net ecosystem productivity, and ecosystem and soil respiration) in control and treatment groups were extracted from each publication when possible. SigmaScan 5.0 (SPSS, Inc.) was used to digitize the figures and extract the numerical values when a publication presented the data graphically. In our meta-analysis, experimental data were excluded if the experiments were conducted over less than one year/growing season, except for tundra studies for which most of measurements were performed during the growing season (July-August). In total, 4,010 observations from single-factor experiments and 1,013 observations from multifactor experiments were collected (Supplementary Table 2). In addition, experimental data of the last year/growing season were used in our analyses when multiple measurements were taken at different years/growing seasons in a study to meet the statistical assumption of independence among samples in the metaanalysis ${ }^{86}$, based on the methods reported in several previous meta-analyses ${ }^{1,64,69}$. After checking for independence, that is, only keeping data of the last year/ growing season in the meta-analyses when multiple measurements were taken at different years/growing seasons in a study, 2,104 observations from single-factor experiments and 392 observations from multifactor experiments in total were used in our meta-analysis (Supplementary Table 3).

The natural log-transformed response ratio (RR) was used to estimate the effect size of global change treatments on ecosystem carbon-cycle variables as:

$$
\operatorname{lnRR}=\ln \left(\frac{\bar{X}_{\mathrm{T}}}{\bar{X}_{\mathrm{C}}}\right)
$$

with a variance of:

$$
\operatorname{var}(\mathrm{RR})=\frac{\mathrm{s} \cdot \mathrm{d}_{\mathrm{T}}^{2}}{n_{\mathrm{T}} \bar{X}_{\mathrm{T}}^{2}}+\frac{\mathrm{s} \cdot \mathrm{d}_{\mathrm{C}}^{2}}{n_{\mathrm{C}} \bar{X}_{\mathrm{C}}^{2}}
$$

where $\bar{X}_{\mathrm{T}}$ s.d. ${ }_{\mathrm{T}}$, and $n_{\mathrm{T}}$ represent the mean, standard deviation and sample size of treatment $(\mathrm{T})$ group, respectively, $\bar{X}_{\mathrm{C}}$, s.d.c and $n_{\mathrm{C}}$ are the mean, standard deviation and sample size of control (C) group, respectively. Based on the methods developed by a previous study ${ }^{87}$, the $\ln \mathrm{RR}$ was calculated separately for each control-treatment pair and treated as independent data when data extracted from multifactor experiments which had multiple single-factor treatments and a single control.

The metafor ${ }^{88}$ package in R software ${ }^{89}$ was used to calculate the weighted response ratio (ln $\mathrm{RR}_{++}$) and bias-corrected $95 \%$ bootstrap-confidence interval (CI) using inverse-variance weighted regressions and random-effects models. Moreover, the publication bias was also evaluated by funnel plots (that is, the scatter plots of the treatment effect sizes against their standard errors $)^{90}$. If the studies were distributed symmetrically in a 'funnel' shape around a mean effect size, it would indicate the absence of publication bias. Therefore, we further assessed the potential asymmetry of the funnel plots using Egger's regression ${ }^{90}$. Results of funnel plots and Egger's regressions under the W, increased precipitation (IP), decreased precipitation (DP), $\mathrm{eCO}_{2}$ and $\mathrm{eN}$ treatments are provided in Supplementary Figs. $7-11$, respectively. We found that publication bias in our meta-analyses was rare. However, there was also some evidence for publication bias: for example, the studies examining the $\mathrm{eCO}_{2}$ effects on GEP (Supplementary Fig. S10; $z=3.84$, $P<0.01)$. Finally, percentage change (\%) of treatment effects was evaluated as:

$$
\text { Percentage change }=\left(\mathrm{e}^{\operatorname{lnRR}_{++}}-1\right) \times 100
$$

If the $95 \%$ CIs of treatment effects did not cover zero, the responses of ecosystem carbon-cycle variables to global change drivers were statistically significant. In addition, responses of ecosystem carbon-cycle variables with different ecosystem types were considered to be significantly different if their 95\% CI values did not overlap.

Furthermore, we standardized the effects of IP/DP across the studies that manipulated different levels of precipitation treatments to compare the differences in precipitation influences among ecosystems and wetness indices based on the methods developed by a previous study ${ }^{23}$. All of the levels of precipitation manipulations were converted into a percentage of MAP. Overall, the manipulations in the IP treatments ranged from $1.1 \%$ to $151.0 \%$ of the MAP, with a median of $35.1 \%$, and the manipulations in the DP treatments ranged from 
$5.8 \%$ to $100 \%$ of the MAP, with a median of $32.3 \%$. We pooled all the studies to determine the absolute values of their manipulation levels, and the median was $32.9 \%$ of the MAP for the whole database. The meta-regressions conducted in the metafor package indicated that the RRs of net primary productivity and its aboveand belowground components, total, aboveground and root biomass, root-to-shoot ratios, litter mass, gross and net ecosystem productivity, and ecosystem and soil respiration showed linear responses to precipitation manipulation levels across all of the precipitation studies (Supplementary Fig. 12). Therefore, we performed the following linear transformation to normalize the RRs of all the carbon-cycle variables under the different treatment/manipulation levels to $32.9 \%$ of the MAP

$$
\bar{X}_{\mathrm{NT}}=\bar{X}_{\mathrm{C}}+\frac{\bar{X}_{\mathrm{T}}-\bar{X}_{\mathrm{C}}}{P} \times 32.9
$$

where $\bar{X}_{\mathrm{NT}}$ is the normalized value under $32.9 \%$ above or below the MAP, and $P$ is the precipitation manipulation levels ( $\%$ of the MAP), with positive values representing the IP treatments and negative values indicating the DP treatments. The normalized $\ln \mathrm{RR}_{++}$and $95 \%$ CIs for changing precipitation studies were also calculated using the metafor package in R software. Results of funnel plots and Egger's regressions under the normalized IP and DP treatments are provided in Supplementary Figs. 13 and 14, respectively. In addition, meta-regressions were conducted to examine the correlations of the normalized $\ln R_{+_{++}}$with wetness indices using the inverse-variance weighted regressions.

To explore which factors could determine the variations of the $\mathrm{eCO}_{2}$ effects (RR) on ecosystem carbon-cycle variables among sites, meta-regressions were also used to examine the correlations of the $\mathrm{eCO}_{2}$ effects with $\mathrm{eCO}_{2}$ levels (ppm), MAP and wetness indices. In addition, we also investigated whether the depths of root biomass sampling affect the responses of root-to-shoot ratios to individual global change drivers using meta-regressions.

Interaction evaluations of multiple global change drivers on ecosystem carboncycle variables. Given that there was not enough data available from three- and four-factor experiments to analyse interactions among three and four global change drivers, we only estimated interactive effects of two-driver pairs using 80 two-factor experiments (362 observations in total; Supplementary Table 4). If a two-factor experiment included four treatments (the control, treatment A, treatment B, and treatment A plus B), based on the techniques developed by two previous studies $^{62,87}$, the interactions were calculated as:

$$
\ln (\mathrm{RR})=\ln \left(\frac{\bar{X}_{\mathrm{AB}}}{\bar{X}_{\mathrm{B}}}\right)-\ln \left(\frac{\bar{X}_{\mathrm{A}}}{\bar{X}_{\mathrm{C}}}\right)
$$

with a variance (the multiplicative property of variances ${ }^{87}$ of:

$$
\operatorname{var}(\mathrm{RR})=\frac{\mathrm{s} \cdot \mathrm{d}_{\mathrm{AB}}^{2}}{n_{\mathrm{AB}} \bar{X}_{\mathrm{AB}}^{2}}+\frac{\mathrm{s} \cdot \mathrm{d}_{\mathrm{B}}^{2}}{n_{\mathrm{B}} \bar{X}_{\mathrm{B}}^{2}}+\frac{\mathrm{s} \cdot \mathrm{d}_{\mathrm{A}}^{2}}{n_{\mathrm{A}} \bar{X}_{\mathrm{A}}^{2}}+\frac{\mathrm{s} \cdot \mathrm{d}_{\mathrm{C}}^{2}}{n_{\mathrm{C}} \bar{X}_{\mathrm{C}}^{2}}
$$

where $\bar{X}_{\mathrm{AB}}$, s.d. ${ }_{\mathrm{AB}}$ and $n_{\mathrm{AB}} ; \bar{X}_{\mathrm{B}}$, s.d.B and $n_{\mathrm{B}} ; \bar{X}_{\mathrm{A}}$, s.d. ${ }_{\mathrm{A}}$ and $n_{\mathrm{A}} ; \bar{X}_{\mathrm{C}}$, s.d.C and $n_{\mathrm{C}}$ represent the mean, standard deviation and sample size of the group of treatment A plus $B$, treatment $B$, treatment $A$ and control, respectively. In the calculation of the interaction term, experimental data of the last year/growing season were used in the metafor package when multiple measurements were taken at different years/growing seasons. Results of funnel plots and Egger's regressions under the interactions between $\mathrm{W}$ and $\mathrm{IP}(\mathrm{W} \times \mathrm{IP}), \mathrm{W}$ and $\mathrm{DP}(\mathrm{W} \times \mathrm{DP}), \mathrm{W}$ and $\mathrm{eCO}_{2}$ $\left(\mathrm{W} \times \mathrm{eCO}_{2}\right), \mathrm{W}$ and $\mathrm{eN}(\mathrm{W} \times \mathrm{eN}), \mathrm{IP}$ and $\mathrm{eN}(\mathrm{IP} \times \mathrm{eN}), \mathrm{DP}$ and $\mathrm{eCO}_{2}\left(\mathrm{DP} \times \mathrm{eCO}_{2}\right)$ and $\mathrm{eCO}_{2}$ and $\mathrm{eN}(\mathrm{eCO} \times \mathrm{eN})$ are provided in Supplementary Figs. 15-20, respectively. However, caution should be taken when using our datasets, because we used fewer than three studies per group to test for publication bias for some two-driver interactions.

Based on a previous study that defined the calculation of interactions ${ }^{62}$ the interactions between two factors were classified into three types, including multiplication, positive interactions and negative interactions. If the $95 \% \mathrm{CI}$ of the interaction term overlapped with zero, the interactive effect was considered to be multiplicative. If not, there were positive (the interaction term $>0$ ) or negative interactions (the interaction term $<0$ ).

Sensitivity of ecosystem carbon-cycle variables in response to global change drivers. Further calculations were performed to analyse sensitivity of ecosystem carbon-cycle variables to global change drivers as a standardized response magnitude per unit change in the global change driver. First, the main effects $(E)$ of global change drivers on ecosystem carbon-cycle variables at each experiment were calculated using formula (4), which gives a percentage change. Second, the sensitivity $(S)$ of ecosystem carbon-cycle variables to $\mathrm{W}\left(S_{\mathrm{W}}\right.$, percentage change per $1{ }^{\circ} \mathrm{C}^{-1}$ increase $)$, IP $\left(S_{\mathrm{IP}}\right.$ percentage change per $10 \mathrm{~mm}$ increase $)$, DP $\left(S_{\mathrm{DP}}\right.$ percentage change per $10 \mathrm{~mm}$ decrease $), \mathrm{eCO}_{2}\left(\mathrm{~S}_{\mathrm{eCO}}\right.$, percentage change per 100 ppm increase) and eN ( $S_{\mathrm{eN}}$, percentage change per $1 \mathrm{~g} \mathrm{~N} \mathrm{~m}^{-2} \mathrm{yr}^{-1}$ addition) in each experiment was calculated as:

$$
S_{\mathrm{W}}=\frac{E}{\text { Increase in temperature }\left({ }^{\circ} \mathrm{C}\right)}
$$

$$
\begin{gathered}
S_{\mathrm{IP}}=\frac{E}{\frac{\text { Increase in precipitation amount }(\mathrm{mm})}{10}} \\
S_{\mathrm{DP}}=\frac{E}{\frac{\text { Decrease in precipitation amount }(\mathrm{mm})}{10}} \\
S_{\mathrm{eCO}_{2}}=\frac{E}{\text { Increase in } \mathrm{CO}_{2} \text { concentration }(\mathrm{ppm})} \times 100 \\
S_{\mathrm{eN}}=\frac{E}{\mathrm{~N} \text { addition rates }\left(\mathrm{g} \mathrm{N} \mathrm{m}^{-2} \mathrm{yr}^{-1}\right)}
\end{gathered}
$$

The units of warming $\left(1^{\circ} \mathrm{C}\right.$ increase $), \mathrm{eCO}_{2}$ (100 ppm increase $)$ and $\mathrm{N}$ addition $\left(1 \mathrm{~g} \mathrm{~N} \mathrm{~m}^{-2} \mathrm{yr}^{-1}\right.$ addition) sensitivities were selected based on two previous studies ${ }^{5,44}$ Moreover, given that effective rainfall is generally more than $5 \mathrm{~mm}$, we calculated precipitation sensitivities as $10 \mathrm{~mm}$ increase or decrease in precipitation. Third, the weighted mean sensitivities of ecosystem carbon-cycle variables to global change drivers at global/ecosystem scales were calculated using the same method as the meta-analysis (bias-corrected $95 \%$ bootstrap-confidence interval using inversevariance weighted regressions and random-effects models).

To investigate whether the local climate conditions influence the sensitivity of ecosystem carbon-cycle variables in response to global change drivers, simple linear regressions with 95\% CIs were conducted to examine the dependences of the warming sensitivity of ecosystem carbon-cycle variables on local MAT, and the relationships of the IP and DP sensitivity of ecosystem carbon-cycle variables on local MAP and wetness indices.

We also plotted the observed against their predicted effects of global change drivers on carbon-cycle variables at each experiment, to examine the predictive ability of our sensitivity database. The observed effects of global change drivers on carbon-cycle variables at an experiment are the influences reported directly in publications collected in this study. The predicted effects were calculated as the product of the magnitudes of experimental manipulations (for example, temperature increases in warming experiments) at the experiment and the sensitivity calculated from the other experiments (Supplementary Figure 5).

Reporting Summary. Further information on the research design is available in the Nature Research Reporting Summary linked to this article.

\section{Data availability}

The data supporting the results can be found in Song, J., Wan, S., Ru, J., Zhou, Z., Shao, P., Han, H., Lei, L., Wang, J., Li, X., Zhang, Q., Li, X., Su, F., Liu, B., Yang, F., Ma, G., Zhang, K., Hu, M., Yan, C., Zhang, A., Zhong, M., Hui, Y., Li, Y. \& Zheng, M. Figshare https://doi.org/10.6084/m9.figshare.7442915.

Received: 23 March 2018; Accepted: 10 July 2019;

Published online: 19 August 2019

\section{References}

1. Curtis, P. S. \& Wang, X. A meta-analysis of elevated $\mathrm{CO}_{2}$ effects on woody plant mass, form, and physiology. Oecologia 113, 299-313 (1998).

2. Rustad, L. E. et al. A meta-analysis of the responses of soil respiration, net nitrogen mineralization, and aboveground plant growth to experimental ecosystem warming. Oecologia 126, 543-562 (2001).

3. Xia, J. \& Wan, S. Global response patterns of terrestrial plant species to nitrogen addition. New Phytol. 179, 428-439 (2008).

4. Lin, D., Xia, J. \& Wan, S. Climate warming and biomass accumulation of terrestrial plants: a meta-analysis. New Phytol. 188, 187-198 (2010).

5. Wu, Z., Dijkstra, P., Koch, G. W., Peñuelas, J. \& Hungate, B. A. Responses of terrestrial ecosystem to temperature and precipitation change: a meta-analysis of experimental manipulation. Global Change Biol. 17, 927-942 (2011).

6. Beier, C. et al. Precipitation manipulation experiments-challenges and recommendations for the future. Ecol. Lett. 15, 899-911 (2012).

7. Knapp, A. K. et al. A reality check for climate change experiments: do they reflect the real world? Ecology 99, 2145-2151 (2018).

8. Kardol, P., De Long, J. R. \& Sundqvist, M. K. Crossing the threshold: the power of multi-level experiments in identifying global change responses. New Phytol. 196, 323-326 (2012).

9. Dukes, J. S., Classen, A. T., Wan, S. \& Langley, J. A. Using results from global change experiments to inform land model development and calibration. New Phytol. 204, 744-746 (2014).

10. De Kauwe, M. G. et al. Where does the carbon go? A model-data intercomparison of vegetation carbon allocation and turnover processes at two temperate forest free-air $\mathrm{CO}_{2}$ enrichment sites. New Phytol. 203, 883-899 (2014) 
11. Medlyn, B. E. et al. Using ecosystem experiments to improve vegetation models. Nat. Clim. Change 5, 528-534 (2015).

12. Norby, R. J. et al. Model-data synthesis for the next generation of forest free-air $\mathrm{CO}_{2}$ enrichment (FACE) experiments. New Phytol. 209, 17-28 (2016).

13. Wang, X. et al. A two-fold increase of carbon cycle sensitivity to tropical temperature variations. Nature 506, 212-215 (2014).

14. Ahlström, A. et al. The dominant role of semi-arid ecosystems in the trend and variability of the land $\mathrm{CO}_{2}$ sink. Science 348, 895-899 (2015).

15. Schuur, E. A. G. et al. Climate change and the permafrost carbon feedback. Nature 520, 171-179 (2015).

16. IPCC Climate Change 2014: Synthesis Report (eds. Core Writing Team, Pachauri R. K. \& Meyer L. A.) (IPCC, 2014).

17. Lamarque, J.-F. et al. Global and regional evolution of short-lived radiativelyactive gases and aerosols in the Representative Concentration Pathways. Clim. Change 109, 191-212 (2011).

18. Melillo, J. M. et al. Soil warming, carbon-nitrogen interactions, and forest carbon budgets. Proc. Natl Acad. Sci. USA 108, 9508-9512 (2011).

19. Hopkins, F. M., Torn, M. S. \& Trumbore, S. E. Warming accelerates decomposition of decades-old carbon in forest soils. Proc. Natl Acad. Sci. USA 109, E1753-E1761 (2012).

20. Hoeppner, S. S. \& Dukes, J. S. Interactive responses of old-field plant growth and composition to warming and precipitation. Global Change Biol. 18, 1754-1768 (2012).

21. Liu, W., Zhang, Z. \& Wan, S. Predominant role of water in regulating soil and microbial respiration and their responses to climate change in a semiarid grassland. Global Change Biol. 15, 184-195 (2009).

22. Reich, P. B. et al. Effects of climate warming on photosynthesis in boreal tree species depend on soil moisture. Nature 562, 263-267 (2018).

23. Liu, L. et al. A cross-biome synthesis of soil respiration and its determinants under simulated precipitation changes. Global Change Biol. 22, 1394-1405 (2016).

24. Mahecha, M. D. et al. Global convergence in the temperature sensitivity of respiration at ecosystem level. Science 329, 838-840 (2010).

25. Dacal, M., Bradford, M. A., Plaza, C., Maestre, F. T. \& García-Palacios, P. Soil microbial respiration adapts to ambient temperature in global drylands. Nat. Ecol. Evol. 3, 232-238 (2019).

26. Knapp, A. K. \& Smith, M. D. Variation among biomes in temporal dynamics of aboveground primary production. Science 291, 481-484 (2001).

27. Knapp, A. K. et al. Consequences of more extreme precipitation regimes for terrestrial ecosystems. BioScience 58, 811-821 (2008).

28. Knapp, A. K., Ciais, P. \& Smith, M. D. Reconciling inconsistencies in precipitation-productivity relationships: implications for climate change. New Phytol. 214, 41-47 (2017).

29. Huxman, T. E. et al. Convergence across biomes to a common rain-use efficiency. Nature 429, 651-654 (2004).

30. Smith, M. D. et al. Global environmental change and the nature of aboveground net primary productivity responses: insights from long-term experiments. Oecologia 177, 935-947 (2015).

31. Trugman, A. T. et al. Tree carbon allocation explains forest drought-kill and recovery patterns. Ecol. Lett. 21, 1552-1560 (2018).

32. Litton, C. M., Raich, J. W. \& Ryan, M. G. Carbon allocation in forest ecosystems. Global Change Biol. 13, 2089-2109 (2007).

33. Meier, I. C. \& Leuschner, C. Belowground drought response of European beech: fine root biomass and carbon partitioning in 14 mature stands across a precipitation gradient. Global Change Biol. 14, 2081-2095 (2008).

34. Vicca, S. et al. Urgent need for a common metric to make precipitation manipulation experiments comparable. New Phytol. 195, 518-522 (2012).

35 . Reinsch, S. et al. Shrubland primary production and soil respiration diverge along European climate gradient. Sci. Rep. 7, 43952 (2017).

36. Leakey, A. D. B. et al. Elevated $\mathrm{CO}_{2}$ effects on plant carbon, nitrogen, and water relations: six important lessons from FACE. J. Exp. Bot. 60, 2859-2876 (2009).

37. Mooney, H. A., Drake, B. G., Luxmoore, R. J., Oechel, W. C. \& Pitelka, L. F. Predicting ecosystem responses to elevated $\mathrm{CO}_{2}$ concentrations. BioScience 41, 96-104 (1991).

38. Fatichi, S. et al. Partitioning direct and indirect effects reveals the response of water-limited ecosystems to elevated $\mathrm{CO}_{2}$. Proc. Natl Acad. Sci. USA 113 , 12757-12762 (2016)

39. Hovenden, M. J., Newton, P. C. D. \& Wills, K. E. Seasonal not annual rainfall determines grassland biomass response to carbon dioxide. Nature 511, 583-586 (2014).

40. Hovenden, M. J. et al. Globally consistent influences of seasonal precipitation limit grassland biomass response to $\mathrm{CO}_{2}$. Nat. Plants 5, 167-173 (2019).

41. Obermeier, W. A. et al. Reduced $\mathrm{CO}_{2}$ fertilization effect in temperate $\mathrm{C}_{3}$ grasslands under more extreme weather conditions. Nat. Clim. Change 7, 137-141 (2017).

42. Norby, R. J., Wullschleger, S. D., Gunderson, C. A., Johnson, D. W. \& Ceulemans, R. Tree responses to rising $\mathrm{CO}_{2}$ : implications for the future forest Plant Cell Environ. 22, 683-714 (1999).
43. Terrer, C., Vicca, S., Hungate, B. A., Phillips, R. P. \& Prentice, I. C. Mycorrhizal association as a primary control of the $\mathrm{CO}_{2}$ fertilization effect. Science 353, 72-74 (2016).

44. Piao, S. et al. Evaluation of terrestrial carbon cycle models for their response to climate variability and to $\mathrm{CO}_{2}$ trends. Global Change Biol. 19, 2117-2132 (2013).

45. Nie, M., Lu, M., Bell, J., Raut, S. \& Pendall, E. Altered root traits due to elevated $\mathrm{CO}_{2}$ : a meta-analysis. Global Ecol. Biogeogr. 22, 1095-1105 (2013).

46. Suter, D. et al. Elevated $\mathrm{CO}_{2}$ increases carbon allocation to the roots of Lolium perenne under free-air $\mathrm{CO}_{2}$ enrichment but not in a controlled environment. New Phytol. 154, 65-75 (2002).

47. Arnone, J. A. et al. Dynamics of root systems in native grasslands: effects of elevated atmospheric $\mathrm{CO}_{2}$. New Phytol. 147, 73-85 (2000).

48. Iversen, C. M. Digging deeper: fine-root responses to rising atmospheric $\mathrm{CO}_{2}$ concentration in forested ecosystems. New Phytol. 186, 346-357 (2010).

49. Hungate, B. A. et al. The fate of carbon in grasslands under carbon dioxide enrichment. Nature 388, 576-579 (1997).

50. Van Groenigen, K. J., Qi, X., Osenberg, C. W., Luo, Y. \& Hungate, B. A. Faster decomposition under increased atmospheric $\mathrm{CO}_{2}$ limits soil carbon storage. Science 344, 508-509 (2014).

51. Song, J. et al. Elevated $\mathrm{CO}_{2}$ does not stimulate carbon sink in a semi-arid grassland. Ecol. Lett. 22, 458-468 (2019).

52. Luo, Y. \& Weng, E. Dynamic disequilibrium of the terrestrial carbon cycle under global change. Trends Ecol. Evol. 26, 96-104 (2011).

53. LeBauer, D. S. \& Treseder, K. K. Nitrogen limitation of net primary productivity in terrestrial ecosystems is globally distributed. Ecology $\mathbf{8 9}$ 371-379 (2008)

54. Janssens, I. A. et al. Reduction of forest soil respiration in response to nitrogen deposition. Nat. Geosci. 3, 315-322 (2010).

55. Vicca, S. et al. Fertile forests produce biomass more efficiently. Ecol. Lett. 15, 520-526 (2012)

56. Verlinden, M. S. et al. Favorable effect of mycorrhizae on biomass production efficiency exceeds their carbon cost in a fertilization experiment. Ecology 99, 2525-2534 (2018).

57. Friedlingstein, P., Joel, G., Field, C. B. \& Fung, I. Y. Toward an allocation scheme for global terrestrial carbon models. Global Change Biol. 5 , 755-770 (1999).

58. Smithwick, E. A., Lucash, M. S., McCormack, M. L. \& Sivandran, G. Improving the representation of roots in terrestrial models. Ecol. Modell. 291, 193-204 (2014)

59. Ye, C. et al. Reconciling multiple impacts of nitrogen enrichment on soil carbon: plant, microbial and geochemical controls. Ecol. Lett. 21 1162-1173 (2018)

60. Leuzinger, S. et al. Do global change experiments overestimate impacts on terrestrial ecosystems? Trends Ecol. Evol. 26, 236-241 (2011).

61. Dieleman, W. I. J. et al. Simple additive effects are rare: a quantitative review of plant biomass and soil process responses to combined manipulations of $\mathrm{CO}_{2}$ and temperature. Global Change Biol. 18, 2681-2693 (2012).

62. Baig, S., Medlyn, B. E., Mercado, L. M. \& Zaehle, S. Does the growth response of woody plants to elevated $\mathrm{CO}_{2}$ increase with temperature? A model-oriented meta-analysis. Global Change Biol. 21, 4303-4319 (2015).

63. Zhou, L. et al. Interactive effects of global change factors on soil respiration and its components: a meta-analysis. Global Change Biol. 22, 3157-3169 (2016).

64. Yue, K. et al. Influence of multiple global change drivers on terrestrial carbon storage: additive effects are common. Ecol. Lett. 20, 663-672 (2017).

65. Larsen, K. S. et al. Reduced N cycling in response to drought, warming, and elevated $\mathrm{CO}_{2}$ in a Danish heathland: synthesizing results of the CLIMAITE project after two years of treatments. Global Change Biol. 17, 1884-1899 (2011)

66. Hungate, B. A., Dukes, J. S., Shaw, M. R., Luo, Y. \& Field, C. B. Nitrogen and climate change. Science 302, 1512-1513 (2003).

67. Shaw, M. R. et al. Grassland responses to global environmental changes suppressed by elevated $\mathrm{CO}_{2}$. Science 298, 1987-1990 (2002).

68. Lu, M. et al. Responses of ecosystem carbon cycle to experimental warming: a meta-analysis. Ecology 94, 726-738 (2013).

69. Wang, X. et al. Soil respiration under climate warming: differential response of heterotrophic and autotrophic respiration. Global Change Biol. 20, 3229-3237 (2014).

70. Wand, S. J., Midgley, G. F., Jones, M. H. \& Curtis, P. S. Responses of wild $\mathrm{C}_{4}$ and $\mathrm{C}_{3}$ grass (Poaceae) species to elevated atmospheric $\mathrm{CO}_{2}$ concentration: a meta-analytic test of current theories and perceptions. Global Change Biol. 5, 723-741 (1999)

71. Ainsworth, E. A. \& Long, S. P. What have we learned from 15 years of free-air $\mathrm{CO}_{2}$ enrichment (FACE)? A meta-analytic review of the responses of photosynthesis, canopy properties and plant production to rising $\mathrm{CO}_{2}$. New Phytol. 165, 351-372 (2005).

72. Luo, Y., Hui, D. \& Zhang, D. Elevated $\mathrm{CO}_{2}$ stimulates net accumulations of carbon and nitrogen in land ecosystems: a meta-analysis. Ecology 87, 53-63 (2006). 
73. Sillen, W. M. A. \& Dieleman, W. I. J. Effects of elevated $\mathrm{CO}_{2}$ and $\mathrm{N}$ fertilization on plant and soil carbon pools of managed grasslands: a meta-analysis. Biogeosciences 9, 2247-2258 (2012).

74. Tian, D., Wang, H., Sun, J. \& Niu, S. Global evidence on nitrogen saturation of terrestrial ecosystem net primary productivity. Environ. Res. Lett. 11, 024012 (2016).

75. De Boeck, H. J. et al. Global change experiments: challenges and opportunities. BioScience 65, 922-931 (2015).

76. Estiarte, M. et al. Few multi-year precipitation-reduction experiments find a shift in the productivity-precipitation relationship. Global Change Biol. 22, 2570-2581 (2016).

77. Kreyling, J., Jentsch, A. \& Beier, C. Beyond realism in climate change experiments: Gradient approaches identify thresholds and tipping points. Ecol. Lett. 17, 125-e1 (2014).

78. Jentsch, A., Kreyling, J. \& Beierkuhnlein, C. A new generation of climate-change experiments: events, not trends. Front. Ecol. Environ. 5, 365-374 (2007).

79. Thompson, R. M., Beardall, J., Beringer, J., Grace, M. \& Sardina, P. Means and extremes: building variability into community-level climate change experiments. Ecol. Lett. 16, 799-806 (2013).

80. Kayler, Z. E. et al. Experiments to confront the environmental extremes of climate change. Front. Ecol. Environ. 13, 219-225 (2015).

81. Zhu, K., Chiariello, N. R., Tobeck, T., Fukami, T. \& Field, C. B. Nonlinear, interacting responses to climate limit grassland production under global change. Proc. Natl Acad. Sci. USA 113, 10589-10594 (2016).

82. Langley, J. A. \& Megonigal, J. P. Ecosystem response to elevated $\mathrm{CO}_{2}$ levels limited by nitrogen-induced plant species shift. Nature 466, 96-99 (2010).

83. Smith, M. D. The ecological role of climate extremes: current understanding and future prospects. J. Ecol. 99, 651-655 (2011).

84. Kreyling, J. et al. To replicate, or not to replicate-that is the question: how to tackle nonlinear responses in ecological experiments. Ecol. Lett. 21, 1629-1638 (2018).

85. De Martonne, E. Une nouvelle fonction climatologique: l'indice d'aridité. $L a$ Météorologie 2, 449-458 (1926).

86. Hedges, L. V., Gurevitch, J. \& Curtis, P. S. The meta-analysis of response ratios in experimental ecology. Ecology 80, 1150-1156 (1999).

87. Lajeunesse, M. J. On the meta-analysis of response ratios for studies with correlated and multi-group designs. Ecology 92, 2049-2055 (2011).

88. Viechtbauer, W. Conducting meta-analyses in $\mathrm{R}$ with the metafor package. J. Stat. Software 36, 1-48 (2010).
89. R Development Core Team. R: A Language and Environment for Statistical Computing (R Foundation for Statistical Computing, 2010).

90. Jennions, M. D., Lortie, C. J., Rosenberg, M. S. \& Rothstein, H. R. in Handbook of Meta-Analysis in Ecology and Evolution (eds Koricheva, J., Gurevitch, J. \& Mengersen, K.) 207-236 (Princeton Univ. Press, 2013).

\section{Acknowledgements}

We thank J. Wang (Hebei University), S. Yang (Institute of Botany, Chinese Academy of Sciences), L. Zhou (East China Normal University), C. Qiao (Xinyang Normal University) and $\mathrm{H}$. Li (Henan University) for their help in meta-analyses and interaction analyses, and H. Li, Y. Liu (Institute of Tibetan Plateau Research, Chinese Academy of Sciences) and Y. He (Peking University) for their help in plotting figures. This work was financially supported by the National Natural Science Foundation of China (grant nos. 31430015 and 31830012). This study emerged from the INTERFACE Workshop in Beijing, China (https://www.bio.purdue.edu/INTERFACE/) supported by the US NSF DEB-0955771. We also acknowledge support from the ClimMani COST action (ES1308).

\section{Author contributions}

S.W. designed the research. J.S., J.R., Z.Z., P.S., H.H., D.W., L. Lei, J.W., Xiaona L., Q.Z., Xiaoming L., F.S., B.L., F.Y., G.M., G.L., Yanchun L., Yinzhan L., Z.Y., K.Z., Y.M., M.H., C.Y., A.Z., M. Zhong, Y.H., Y. Li. and M. Zheng collected the 2,230 publications. J.S., J.R., Z.Z. and Q.L. performed the data extraction and analysis as well as figure plotting. J.S., S.W. and S.P. wrote the first draft of the manuscript, and A.K.K., A.T.C., S.V., P.C., M.J.H., S.L., C.B., P.K., J.X., Y. Luo, D.G., J.A.L., J.Z., J.S.D., J.T., J.C., K.S.H., L.M.K., L.R., L. Liu, M.D.S., P.H.T., R.Q.T., R.J.N., R.P.P., S.N., S.F. and Y.W. contributed substantially to revisions.

\section{Competing interests}

The authors declare no competing interests.

\section{Additional information}

Supplementary information is available for this paper at https://doi.org/10.1038/ s41559-019-0958-3.

Reprints and permissions information is available at www.nature.com/reprints. Correspondence and requests for materials should be addressed to S.W. Publisher's note: Springer Nature remains neutral with regard to jurisdictional claims in published maps and institutional affiliations.

(c) The Author(s), under exclusive licence to Springer Nature Limited 2019

${ }^{1}$ College of Life Sciences, Hebei University, Baoding, China. ${ }^{2}$ International Joint Research Laboratory for Global Change Ecology, School of Life Sciences, Henan University, Kaifeng, China. ${ }^{3}$ Sino-French Institute for Earth System Science, College of Urban and Environmental Sciences, Peking University, Beijing, China. ${ }^{4}$ Key Laboratory of Alpine Ecology, Institute of Tibetan Plateau Research, Chinese Academy of Sciences, Beijing, China. ${ }^{5}$ Center for Excellence in Tibetan Earth Science, Chinese Academy of Sciences, Beijing, China. ${ }^{6}$ Department of Biology, Colorado State University, Fort Collins, CO, USA. ${ }^{7}$ Graduate Degree Program in Ecology, Colorado State University, Fort Collins, CO, USA. ${ }^{8}$ Rubenstein School of Environment and Natural Resources, University of Vermont, Burlington, VT, USA. ${ }^{9}$ Gund Institute for Environment, University of Vermont, Burlington, VT, USA. ${ }^{10}$ Centre of Excellence PLECO (Plant and Vegetation Ecology), Department of Biology, University of Antwerp, Wilrijk, Belgium. "'Laboratoire des Sciences du Climat et de l'Environnement, Gif sur Yvette, France. ${ }^{12}$ Biological Sciences, School of Natural Sciences, University of Tasmania, Hobart, Australia. ${ }^{13}$ Institute for Applied Ecology New Zealand, School of Science, Auckland University of Technology, Auckland, New Zealand. ${ }^{14}$ Department of Geosciences and Natural Resource Management, University of Copenhagen, Copenhagen, Denmark. ${ }^{15}$ Department of Forest Ecology and Management, Swedish University of Agricultural Sciences, Umeå, Sweden. ${ }^{16}$ Zhejiang Tiantong Forest Ecosystem National Observation and Research Station, Shanghai Key Lab for Urban Ecological Processes and EcoRestoration, School of Ecological and Environmental Sciences, East China Normal University, Shanghai, China. ${ }^{17}$ Research Center for Global Change and Ecological Forecasting, East China Normal University, Shanghai, China. ${ }^{18} \mathrm{Center}$ for Ecosystem Study and Society, Department of Biological Sciences, Northern Arizona University, Flagstaff, AZ, USA. ${ }^{19}$ Center for Forest Ecosystem Studies and Qianyanzhou Ecological Station, Key Laboratory of Ecosystem Network Observation and Modeling, Institute of Geographic Sciences and Natural Resources Research, Chinese Academy of Sciences, Beijing, China. ${ }^{20}$ Department of Biology, Villanova University, Villanova, PA, USA. ${ }^{21}$ Institute for Atmospheric and Climate Science, ETH, Zürich, Switzerland. ${ }^{22}$ Climate and Environmental Physics, University of Bern, Bern, Switzerland. ${ }^{23}$ Department of Forestry and Natural Resources and Department of Biological Sciences, Purdue University, West Lafayette, IN, USA. ${ }^{24}$ Marine Biological Laboratory, The Ecosystem Center, Woods Hole, MA, USA. ${ }^{25}$ Center for Global Change and Earth Observations, Department of Geography, Environment and Spatial Sciences, Michigan State University, East Lansing, MI, USA. ${ }^{26}$ Department of Ecology, Evolution, and Organismal Biology, lowa State University, Ames, IA, USA. ${ }^{27}$ Environmental Molecular Sciences Laboratory, Pacific Northwest National Laboratory, Richland, WA, USA. ${ }^{28}$ Energy and Resources Group, University of California, Berkeley, Berkeley, CA, USA. ${ }^{29} \mathrm{Climate}$ and Ecosystem Sciences Division, Lawrence Berkeley National Laboratory, Berkeley, CA, USA. ${ }^{30}$ United States Department of Agriculture Forest Service, Northern Research Station, Durham, NH, USA. ${ }^{31}$ State Key Laboratory of Vegetation and Environmental Change, Institute of Botany, Chinese Academy of Sciences, Beijing, China. ${ }^{32}$ Department of Biology, Boston University, Boston, MA, USA. ${ }^{33}$ Department of Forest Resources and Environmental Conservation, Virginia Tech, Blacksburg, VA, USA. ${ }^{34}$ Environmental Sciences Division and Climate Change Science Institute, Oak Ridge National Laboratory, Oak Ridge, TN, USA. ${ }^{35}$ Department of Biology, Indiana University, Bloomington, IN, USA. ${ }^{36}$ Key Laboratory of Ecosystem Network Observation and Modeling, Institute of Geographic Sciences and Natural Resources Research, Chinese Academy of Sciences, Beijing, China. ${ }^{37}$ Institute of Environmental Engineering, ETH, Zurich, Switzerland. ${ }^{38} \mathrm{CSIRO}$ Oceans and Atmosphere, Victoria, Australia. ${ }^{39}$ Shandong Key Laboratory of Eco-Environmental Science for the Yellow River Delta, Binzhou University, Binzhou, China. *e-mail: swan@ibcas.ac.cn 


\section{Reporting Summary}

Nature Research wishes to improve the reproducibility of the work that we publish. This form provides structure for consistency and transparency in reporting. For further information on Nature Research policies, see Authors \& Referees and the Editorial Policy Checklist.

\section{Statistics}

For all statistical analyses, confirm that the following items are present in the figure legend, table legend, main text, or Methods section.

$\mathrm{n} / \mathrm{a}$ | Confirmed

$\square$ \The exact sample size $(n)$ for each experimental group/condition, given as a discrete number and unit of measurement

$\square$ \ A statement on whether measurements were taken from distinct samples or whether the same sample was measured repeatedly

The statistical test(s) used AND whether they are one- or two-sided

$\square$ Only common tests should be described solely by name; describe more complex techniques in the Methods section.

$\bigotimes \square$ A description of all covariates tested

$\square$ \ A description of any assumptions or corrections, such as tests of normality and adjustment for multiple comparisons

$\square$ A full description of the statistical parameters including central tendency (e.g. means) or other basic estimates (e.g. regression coefficient)

AND variation (e.g. standard deviation) or associated estimates of uncertainty (e.g. confidence intervals)

$\square$ For null hypothesis testing, the test statistic (e.g. $F, t, r$ ) with confidence intervals, effect sizes, degrees of freedom and $P$ value noted

$\square$ Give P values as exact values whenever suitable.

Х $\square$ For Bayesian analysis, information on the choice of priors and Markov chain Monte Carlo settings

$\square \bigotimes$ For hierarchical and complex designs, identification of the appropriate level for tests and full reporting of outcomes

$\square$ Estimates of effect sizes (e.g. Cohen's $d$, Pearson's $r$ ), indicating how they were calculated

Our web collection on statistics for biologists contains articles on many of the points above.

\section{Software and code}

Policy information about availability of computer code

Data collection Peer-reviewed publications that reported ecosystem manipulative experiments in global change research were collected by searching Web of Science (WoS; January 1st, 1900 to December 31th, 2016; Thomson Reuters, New York, NY, USA) to construct the dataset of the synthesis during January-May 2017. Databases used for search in WoS included 1) WoS Core Collection, 2) Inspec ${ }^{\circledast}$, 3) KCl-Korean Journal Database, 4) BIOSIS Previews, 5) Derwent Innovations Index, 6) Russian Science Citation Index, 7) Data Citation Index, 8) Chinese Science Citation Database, 9) MEDLINE ${ }^{\oplus}$, and 10) SciELO Citation Index. Details were reported in data collection section of the Methods.

Data analysis All meta-analyses and meta-regressions were performed using the package 'metafor' in R software (version 3.5.1). Details were reported in statistical analysis section of the Methods.

For manuscripts utilizing custom algorithms or software that are central to the research but not yet described in published literature, software must be made available to editors/reviewers. We strongly encourage code deposition in a community repository (e.g. GitHub). See the Nature Research guidelines for submitting code \& software for further information.

\section{Data}

Policy information about availability of data

All manuscripts must include a data availability statement. This statement should provide the following information, where applicable:

- Accession codes, unique identifiers, or web links for publicly available datasets

- A list of figures that have associated raw data

- A description of any restrictions on data availability

The data supporting the results of this study were archived in Figshare (https://doi.org/10.6084/m9.figshare.7442915). 


\section{Field-specific reporting}

Please select the one below that is the best fit for your research. If you are not sure, read the appropriate sections before making your selection.
Life sciences
Behavioural \& social sciences
$\bigotimes$ Ecological, evolutionary \& environmental sciences

For a reference copy of the document with all sections, see nature.com/documents/nr-reporting-summary-flat.pdf

\section{Ecological, evolutionary \& environmental sciences study design}

All studies must disclose on these points even when the disclosure is negative.

\section{Study description \\ Synthesis study.}

Research sample

In total, we extracted 4010 observations from 850 single factor experiments and 1013 observations from 269 multi-factor experiments for ecosystem carbon-cycle variables including net primary productivity and its above- and below-ground components, total, aboveground, and root biomass, root-to-shoot ratios, litter mass, gross and net ecosystem productivity, and ecosystem and soil respiration (Supplementary Table 2), to perform meta-analysis calculations. We also extracted 362 observations from 80 two-factor experiments for ecosystem carbon-cycle variables (Supplementary Table 4), to estimate the interaction terms among multiple global change drivers.

Sampling strategy

The peer-reviewed publications were searched (title search) using Web of Science covering studies published between 1900 to 2016 with the keywords including 1) global change, 2) climate change, 3) free-air carbon dioxide enrichment, 4) free-air CO2 enrichment, 5) elevated carbon dioxide, 6) elevated $\mathrm{CO} 2,7$ ) elevated atmospheric $\mathrm{CO} 2,8) \mathrm{CO} 2$ enrichment, 9) eCO2, 10) [CO2], 11) warming, 12) elevated temperature, 13) changing precipitation, 14) increased precipitation, 15) decreased precipitation, 16) nitrogen deposition, 17) nitrogen addition, and 18) nitrogen application. Details about the inclusion/ exclusion criteria for publications were reported in data collection section of the Method.

Data collection Peer-reviewed publications that reported ecosystem manipulative experiments in global change research were collected by searching Web of Science (WoS; January 1st, 1900 to December 31th, 2016; Thomson Reuters, New York, NY, USA) to construct the dataset of the synthesis during January-May 2017. Databases used for search in WoS included 1) WoS Core Collection, 2) Inspec $\left.{ }^{\circledR}, 3\right)$ $\mathrm{KCl}$-Korean Journal Database, 4) BIOSIS Previews, 5) Derwent Innovations Index, 6) Russian Science Citation Index, 7) Data Citation Index, 8) Chinese Science Citation Database, 9) MEDLINE ${ }^{\circledR}$, and 10) SciELO Citation Index. Details were reported in data collection section of the Methods.

Timing and spatial scale Together, the studies published between 1973 to 2016, covered seven ecosystems including forests, grasslands, wetlands, tundra, and deserts. The mean annual precipitation (MAP) ranged from $52 \mathrm{~mm}$ to $4239 \mathrm{~mm}$, and the mean annual temperature (MAT) ranged from less than $-19^{\circ} \mathrm{C}$ to greater than $27^{\circ} \mathrm{C}$.

Data exclusions We excluded studies that were conducted in aquatic and agriculture ecosystems. In addition, we collected data from field studies, and excluded those from laboratory incubation studies.

Reproducibility

The methods of data collection and analysis were presented in the Methods section in detail and the data supporting the results of this study were archived in Figshare for reproducibility.

Randomization

The data were analyzed with a random effect model. Details were reported in statistical analysis section of the Method.

Blinding

N/A

Did the study involve field work? $\square$ Yes $\square$ No

\section{Reporting for specific materials, systems and methods}

We require information from authors about some types of materials, experimental systems and methods used in many studies. Here, indicate whether each material, system or method listed is relevant to your study. If you are not sure if a list item applies to your research, read the appropriate section before selecting a response.

\begin{tabular}{|c|c|}
\hline $\mathrm{n} / \mathrm{a}$ & Involved in the study \\
\hline Х & Antibodies \\
\hline$\bigotimes$ & Eukaryotic cell lines \\
\hline Х & Palaeontology \\
\hline$\bigotimes$ & Animals and other organisms \\
\hline Х & Human research participants \\
\hline Х & Clinical data \\
\hline
\end{tabular}

\begin{tabular}{l|l}
\multicolumn{2}{l}{ Methods } \\
\hline n/a & Involved in the study \\
$\bigotimes$ & $\square$ ChIP-seq \\
$\bigotimes$ & $\square$ Flow cytometry \\
$\bigotimes$ & $\square$ MRI-based neuroimaging
\end{tabular}

